\title{
Solid lipid nanoparticles: Preparation techniques, their characterization, and an update on recent studies
}

\author{
Koduru Trideva Sastri*, Gadela Venkata Radha, Sruthi Pidikiti, Priya Vajjhala \\ GITAM Institute of Pharmacy, GITAM Deemed to be University, Visakhapatnam, India.
}

\section{ARTICLE INFO \\ Received on: 03/12/2019 \\ Accepted on: 17/04/2020 \\ Available online: 05/06/2020}

\section{Key words:}

Solid lipid nanoparticles, carrier system, nanomedicine, biocompatibility,

nanotechnology.

\begin{abstract}
Solid lipid nanoparticles (SLNs) have emerged as a remarkable nanocolloidal system for drug delivery. This review presents contemporary information regarding various aspects about SLNs, i.e., SLN morphology, structural features, preparatory methods, and their characterizations. This carrier system allows advancing the therapeutic efficacy of drugs belonging to several categories. The present uses of SLNs include cancer therapy, infectious conditions, diabetes, central nervous system disorders, cardiovascular disorders, cosmeceuticals, and others. SLNs facilitate improved the pharmacokinetics and modify the drug releases. The prospect of surface modification, enhanced permeation against various biological barriers, the ability to resist chemical degradation, and the possibility of encapsulation of two or more therapeutic agents simultaneously has gained attention for SLNs universally. Simultaneously, this review emphasizes on recent research trends pertaining to this carrier system.
\end{abstract}

\section{INTRODUCTION}

In the past few years, there has been a fascinating development in nanoscale drug delivery technologies. Majorly biocompatible polymers and lipid excipients have been on the rise, which efficiently incorporated in the lipid nanosystems. These lipids are usually physiological lipids possessing little acute and chronic toxicities (Hadis et al., 2019; Harde et al., 2011). Solid lipid nanoparticles (SLNs) offer an amalgamating effect of several carrier systems such as liposomes and niosomes. Similar to other carrier systems, SLNs are also constituted by biocompatible excipients that are physiologically accepted and homology to polymeric nanoparticles. The solid matrix in SLNs also proposes to protect the loaded therapeutic molecules against the rough biological environment and also shield the other chemical degradations with maximum feasibility to alter the release profiles of the therapeutic molecule. Altogether, these proficiencies make the SLNs an exceptional carrier system (Das and Chaudhury, 2011).

\section{"Corresponding Author}

Trideva Sastri K, GITAM Institute of Pharmacy, GITAM Deemed to be University,Visakhapatnam, India.E-mail: trideva.k@gmail.com
SLNs are morphologically spherical with a smooth surface possessing mean diameter ranging between 50 and $1,000 \mathrm{~nm}$. Both in vivo and in vitro behaviors are dependent on the physicochemical characterization of SLNs. Solid lipid (at $25^{\circ} \mathrm{C}-28^{\circ} \mathrm{C}$ ), emulsifiers for certain times simultaneously, and along with appropriate solvent for solubilizing lipid and non-lipid components, together constitute the typical SLNs (Fig. 1).

While formulating SLNs, lipids listed in Generally Regarded as Safe are commonly employed (Weber et al., 2014). These comprise of fatty acids/esters, cholesterol, triglycerides (e.g., compritol ${ }^{\circledR} 888$ and caprylic), and waxes (bees, carnauba, etc.). Pluronic F68/F127, poloxamers, and sodium cholate are considered for emulsification. Organic salts, surface modifiers, and ionic polymers are served for PEGylation, specific targeting, surface charge modifications. SLNs are classified into (a) drugloaded shell, (b) drug-loaded core, and (c) homogeneous matrix, based on entrenched site of the therapeutic molecule within the SLN structure. Advantages and applications are shown in Figure 2.

The process of cooling hot liquid droplets followed by phase separation yields a drug-loaded shell. This rapid cooling results in liquid precipitation that forms SLNs on complete cooling. This category of SLNs fits well for topical conditions. Unlike the shell model, drug-loaded core, the drug ought to crystallize much before liquid precipitate. The drug-loaded core model facilitates 
the sustained release of therapeutic agents and obeys Fick's law of diffusion. Highly lipophilic drugs are dispersed homogeneously within the lipid matrix employing cold homogenization. Hence, SLNs benefit in smooth production, employing simple homogenization techniques (Aleksandra et al., 2018; Jenning et al., 2000). A comprehensive understanding of various production techniques is further discussed in the following section.

\section{PREPARATION OF SLN}

\section{High-pressure homogenization}

High-pressure homogenization (HPH) has been used as a reliable technique for the preparation of SLN. Several manufacturers produce homogenizers of diverse sizes at a reasonable cost. The particles of the submicron range are obtained at elevated shear stress and cavitation compulsion. Nanoemulsions for parenteral nutrition

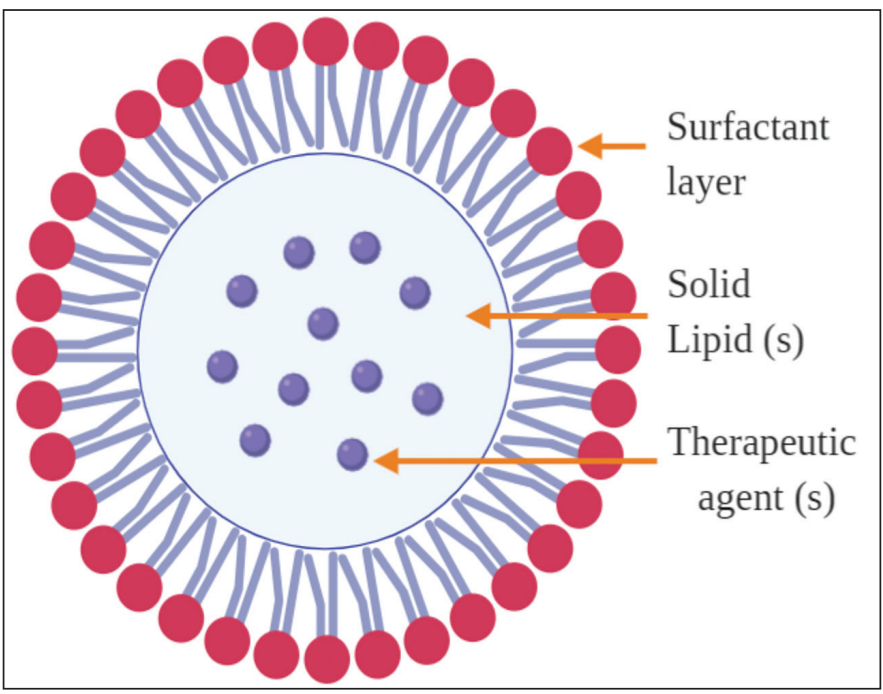

Figure 1. Structure of SLNs. are produced by HPH. HPH pushes the liquid at high pressures (100-2,000 bar) through a narrow space (range of few microns). The fluid moves faster over a short distance with high velocity. With homogenization, even the high lipid concentration could be transformed into nanodispersions (Wolfgang and Karsten, 2001).

Hot and cold homogenization techniques are the means for the manufacturing of SLN. A preparatory step involves in both the cases. Lipid matrix used in this process is extracted from the physiological lipids which reduce the risk of acute and chronic toxicity.

\section{Hot homogenization}

Temperatures higher than the melting point of the lipid are selected for this process and can subsequently be considered as the homogenization of an emulsion. An aqueous surfactant is used for the combination of lipid and drug at the same temperature. A device for high shear mixing is used to prepare a hot pre-emulsion, resulting in an emulsion of oil in water type. Then, the product is left for cooling, and this leads to the initiation of crystals of lipid and then the formation of SLNs. For the production of perfect SLNs, 3-5 cycles of homogenization at a pressure of 500-1,500 bar are necessary (Akanksha et al., 2012). One should always be aware that there is a rise in temperature with HPH. With the rise in the number of cycles or the pressure, there is a growth in the particle size. This is due to attractive forces between the particles which are due to the energy of moving the particles (Siekmann and Westesen, 1994). Finally, cooling of the nanoemulsion to room temperature is done, where the recrystallization of lipids occurs and this leads to the formation of nanoparticles (Fig. 3).

\section{Cold homogenization}

This technique has been developed to combat the problems of hot homogenization such as faster deterioration due to high temperatures, loss of drug during homogenization into the aqueous phase, and undetermined polymorphic transformations of the lipid due to the complexity of crystallization.

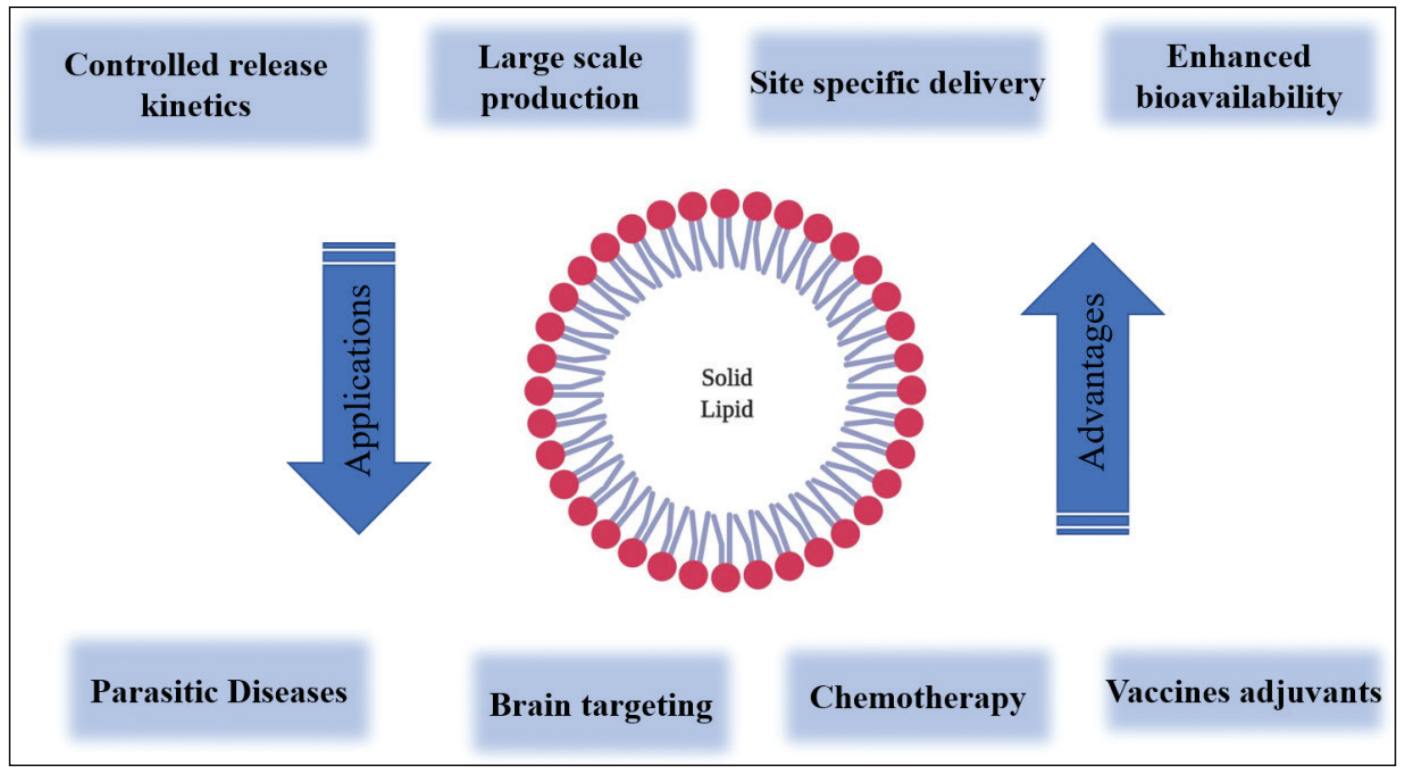

Figure 2. Representation of advantages and applications SLNs formulations. 
The first elementary step is indistinguishable as in the hot homogenization technique which includes the solubilization of drug in the lipid melt. The successive steps are altered; the drug-containing melt is refrigerated speedily with the aid of solid carbon dioxide or liquid nitrogen for attaining a homogenous drug distribution lipid matrix. The solid is then levigated into a fine dust by using a ball mill. Typical dust size attained is in the range of $50-100 \mu \mathrm{m}$. In the chilled aqueous surfactant, the fine dust particles are dispersed. Now, the dispersion is subjected to HPH to initiate the SLN production (Fig. 4). However, compared to a hot homogenization technique, greater particle sizes and wider size distribution are typical of the cold homogenized product (Mehnert and Mäder, 2001)
Cold homogenization lessens the heat vulnerability, but it is not completely avoided due to the softening of lipid mixture in the opening step.

\section{Ultrasonication}

SLN was also produced by high-speed stirring or sonication (Eldem et al., 1991). The impedimenta used for this method is prevalent in every single laboratory. The main drawback of this technique is wider particle size distribution ranging into micrometer range which is the main cause for physical instability (Svilenov and Tzachev, 2009). Particle gain on storage and potential metal decay are acute problems in this method. After many studies and intense research, it was proved that high-speed stirring and

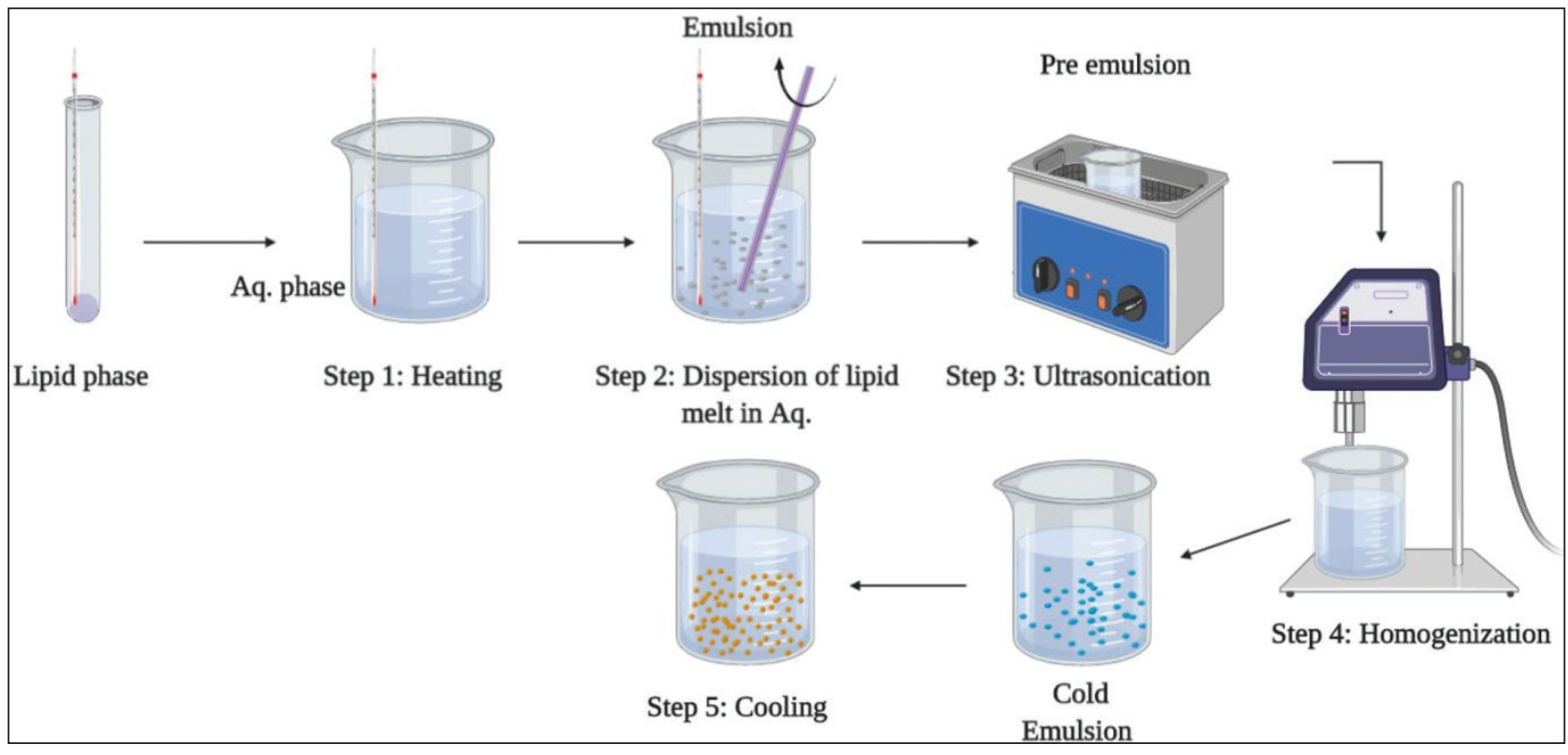

Figure 3. Hot homogenization technique.

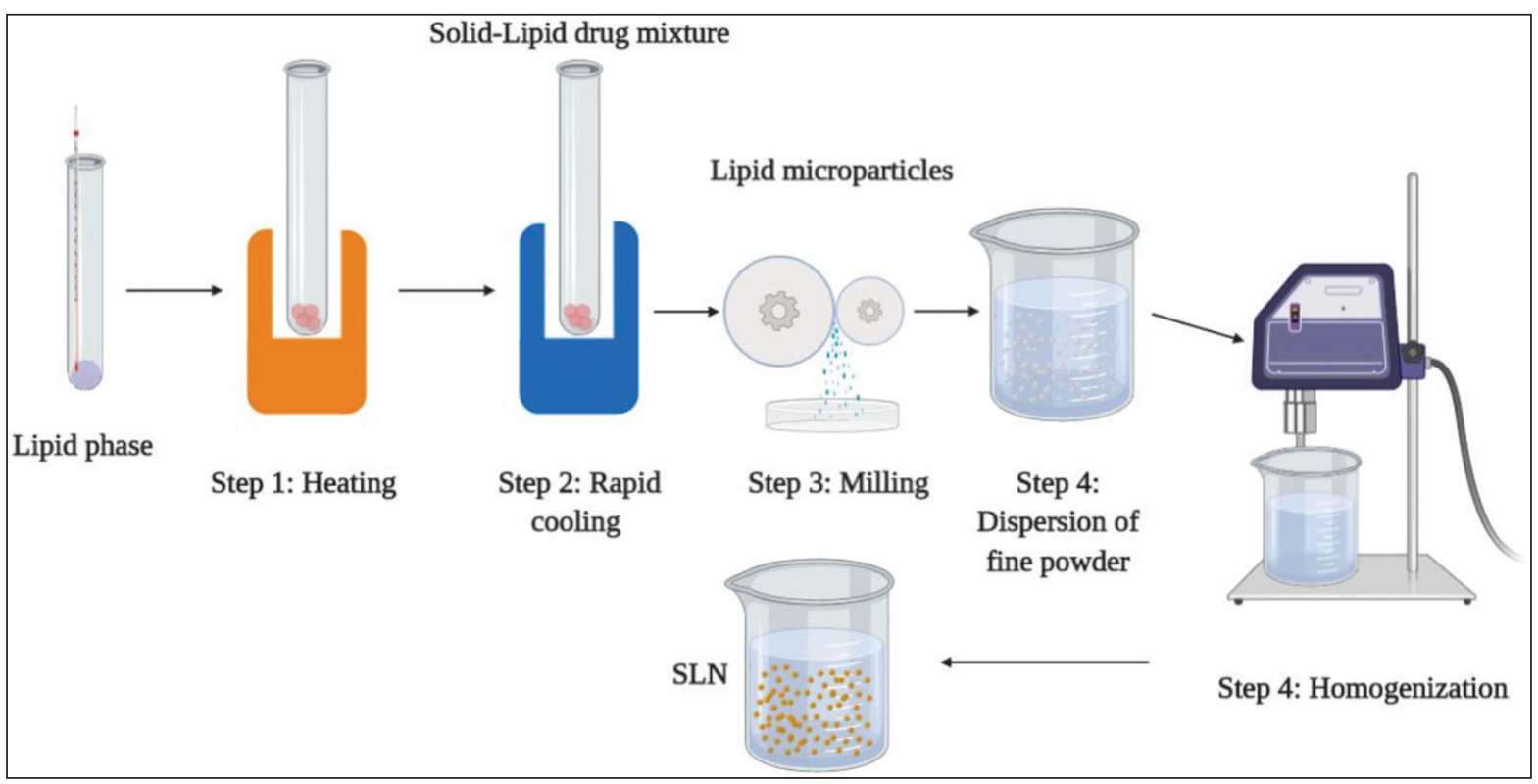

Figure 4. Cold homogenization technique. 
ultrasonication, when operated combinedly at high temperatures, yield a steady formulation (Eldem et al., 1991) (Fig. 5).

\section{Solvent emulsification-evaporation}

In this method, the lipophilic material and hydrophobic drug are dissolved in water-immiscible organic solvents such as cyclohexane, toluene, and chloroform. Now, by using a highspeed homogenization, the mixture is emulsified in an aqueous phase. The coarse emulsion is instantly allowed to flow through a microfluidizer. A rotary evaporator with mechanical agitation at room temperature and decreased pressure is used to evaporate the organic solvent (Ramteke et al., 2012). The main mastery of this technique is bypassing the thermal stress. Therefore, now, there is a possibility for the incorporation of highly thermolabile drugs (Fig. 6). The clear-cut disadvantage is the use of an organic solvent which may react with drug molecules (Sjostrom and Bergenstahl, 1992)

\section{Supercritical fluid (ScF)}

This is a comparatively advanced technique for the manufacturing of SLNs. The supercritical fluid has distinct thermophysical properties which can be finely adjusted by minute modifications in the pressure. It is solvent-free processing (Chen et al., 2006; Kaiser et al., 2001). With the elevation in pressure, the density and capability of fluid to liquefy compounds enhance, whereas the velocity remains the same. $\mathrm{ScF}$ is a substance above its pressure and critical temperature. The fluid has special properties at these conditions: liquid-like density, gas-like viscosity, and larger diffusivities than those of typical liquid (intermediate to that of a liquid and a gas), giving rise to its higher

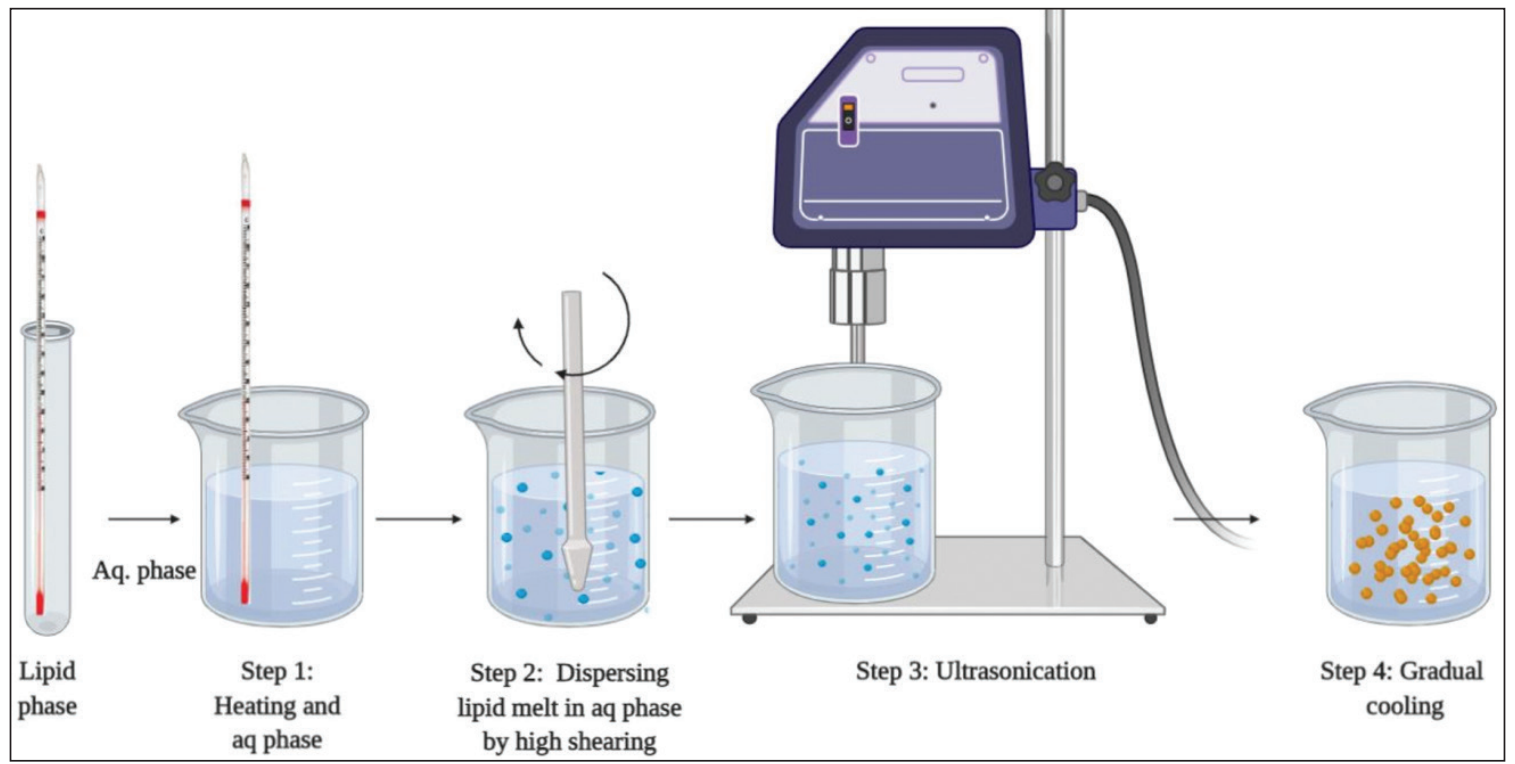

Figure 5. High shear homogenization or ultrasonication technique.

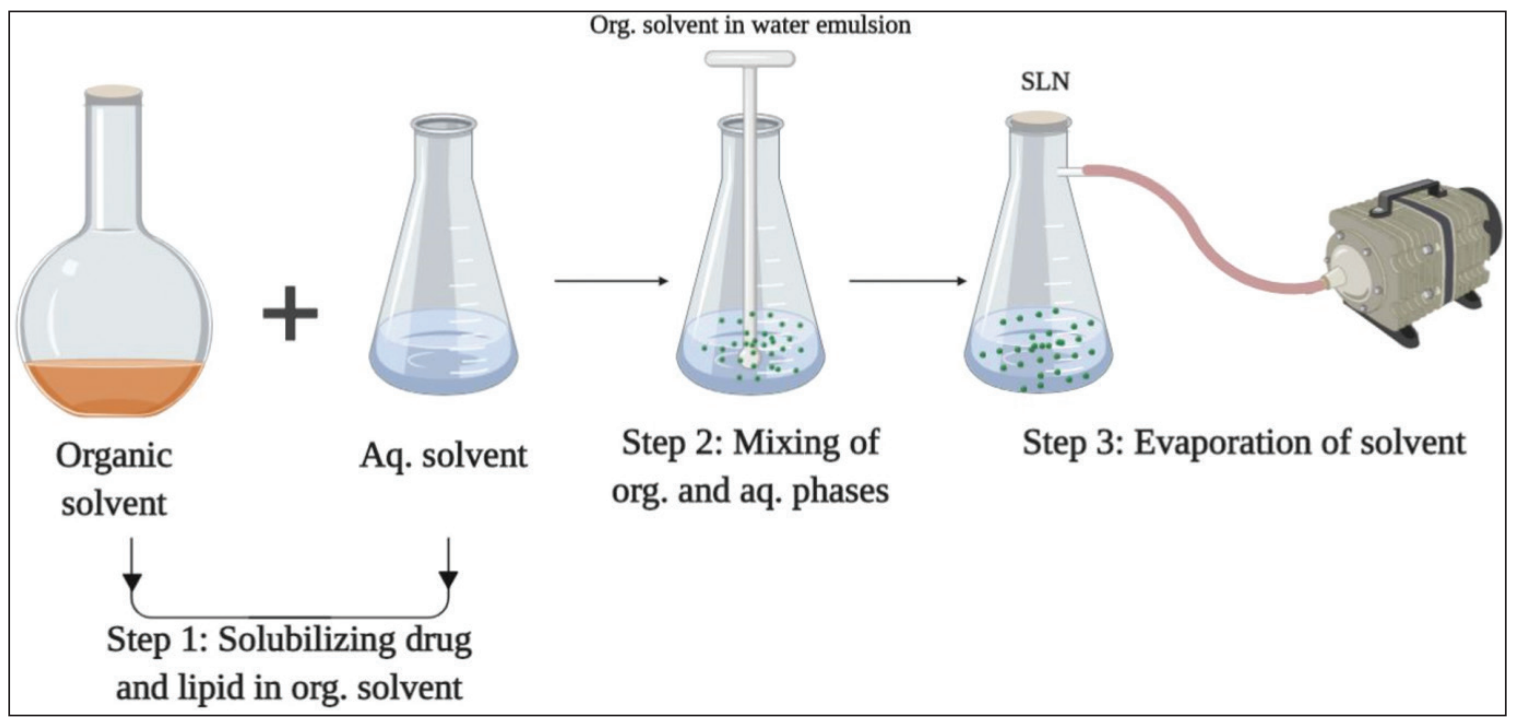

Figure 6. Solvent emulsification-evaporation technique. 
mass-transfer rate. Various techniques such as rapid expansion of supercritical solutions (RESS), supercritical antisolvent process and precipitation with a compressed antisolvent process (PCA), particles from gas-saturated solutions/suspensions, and supercritical extraction from emulsions can be used.

The high solubility of the drug in $\mathrm{ScCO} 2$ (solvent) is required for carrying out RESS technology. In this process, the supercritical fluid is quickly enlarged via a nozzle to convert the solute as micro- or nanoparticles. There are three major factors which regulate the particle, and the particle growth is a short residence time, not much time available for particle growth and maximum dilution of the particles in the expansion chamber (Garces et al., 2018). Pure powder griseofulvin has been acquired using a cosolvent such as methanol which improves the drug solubility in $\mathrm{ScCO} 2$ for about 28 folds. The usage of a simple capillary nozzle, griseofulvin NPs in the range of 50-250 $\mathrm{nm}$ has been derived (Thakur and Gupta, 2005).

In the PCA technique, an atomized drug solution along with compressed carbon dioxide is introduced into the chamber. After the solution gets supersaturated, fine crystals precipitate out. A supercritical fluid with poor drug solubility is selected and used. The drug is dissolved in the solvent. This solvent should be miscible with the supercritical fluid. The supercritical fluids pull out all the solvent, and then, the drug solution becomes supersaturated after introducing the drug solution into the supersaturated solution. The drug precipitates as fine crystals (Alessi et al., 2012). The key advantage of this method is the particles which are acquired as a dry powder, instead of suspension (Fig. 7).

\section{Microemulsion}

SLN preparations were developed by Gasco and coworkers on the basis of reducing the concentration of microemulsions (Akanksha et al., 2012). These microemulsions are biphasic units consisting of external and internal mediums. Combination consists of a low melting fatty acid (e.g., stearic acid), an emulsifier (e.g., polysorbate 20 , polysorbate 60 , and soy phosphatidylcholine), coemulsifiers (e.g., butanol and sodium mono cetyl phosphate), and water. In the cold water $\left(2^{\circ} \mathrm{C}-3^{\circ} \mathrm{C}\right)$, the hot microemulsion is diffused. Based on the combination of microemulsion, the dilution process can be fixed. In this method, there is no extra energy consumed for attaining the submicron size (Gasco, 1997; Ramteke et al., 2012) The main criteria for the production of nanoparticles are that they can be produced only with certain solvents which rapidly distribute into the aqueous phase (Fig. 8), whereas more lipophilic solvents are utilized for obtaining the large particle sizes. The main advantage of this method is low mechanical energy input which is sufficient.

\section{Spray drying}

It is another procedure to lyophilization for the modification of an aqueous dispersion into a drug. It is an economical method when compared to lyophilization. There is a chance of particle gathering due to the elevated temperature, shear forces, and incomplete melting of the particle (Jawahar et al., 2012). Freitas et al. (1998) recommended that the lipids with a boiling point higher than $70^{\circ} \mathrm{C}$ should be selected for spray drying. The best result was procured by spray drying with SLN concentration of $1 \%$ in a solution of trehalose in water or $20 \%$ trehalose in ethanol-water mixtures $(10 / 90 \mathrm{v} / \mathrm{v})$.

\section{Double emulsion}

This method is used for the preparation of hydrophilicloaded SLNs based on solvent emulsification-evaporation (Svilenov and Tzachev, 2014). First, the drug is dissolved in aqueous-based solutions and then dissolved in a liquid melt. A stabilizer is used for the stabilization of the primary emulsion (He et al., 2015). This primary emulsifier is dispersed in the aqueous phase composed of hydrophilic emulsifier. Now, the double emulsion is blended and then separated by sifting (Fig. 9). Poly (lactic-co-glycolic

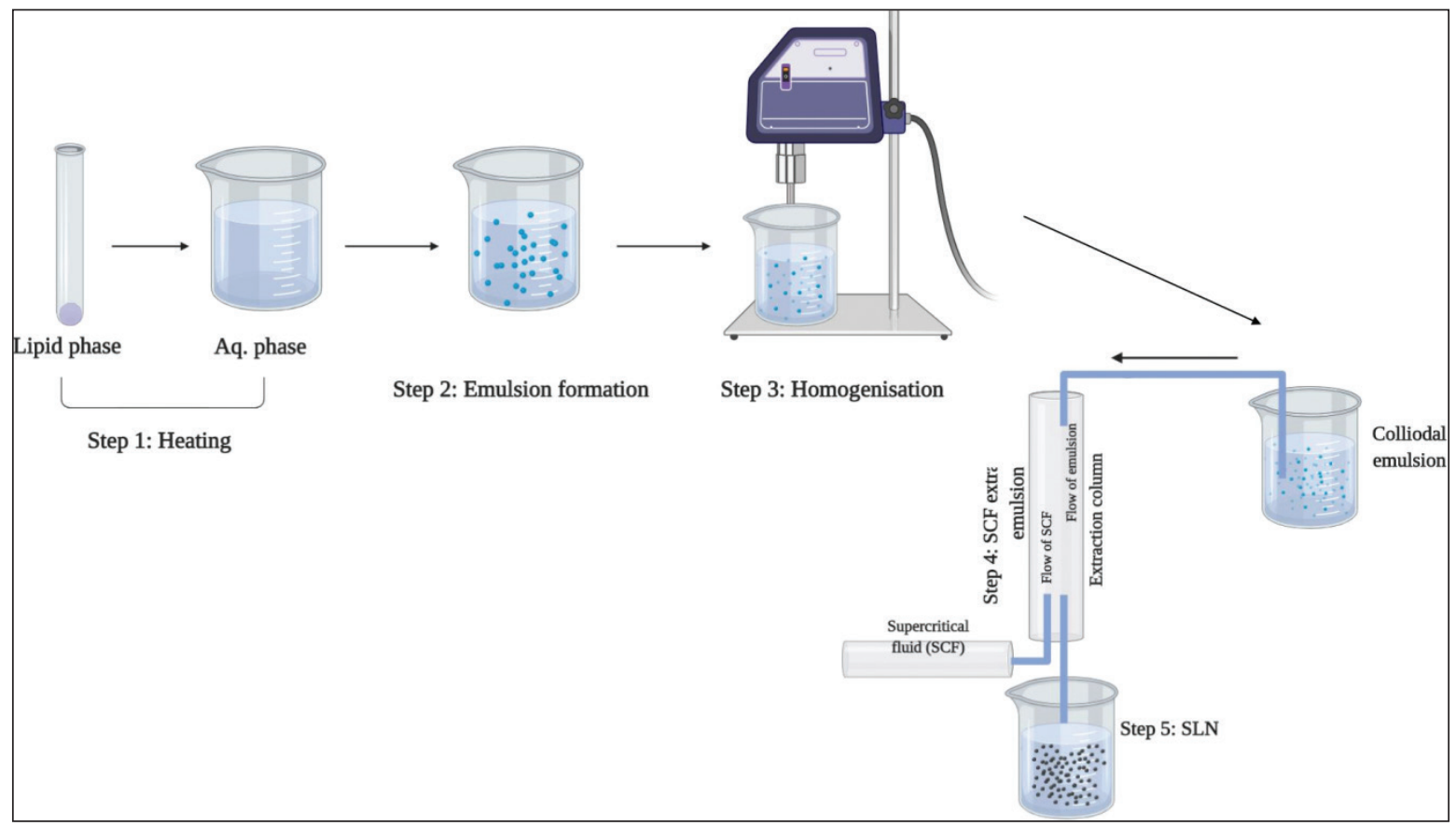

Figure 7. Supercritical fluid technique. 


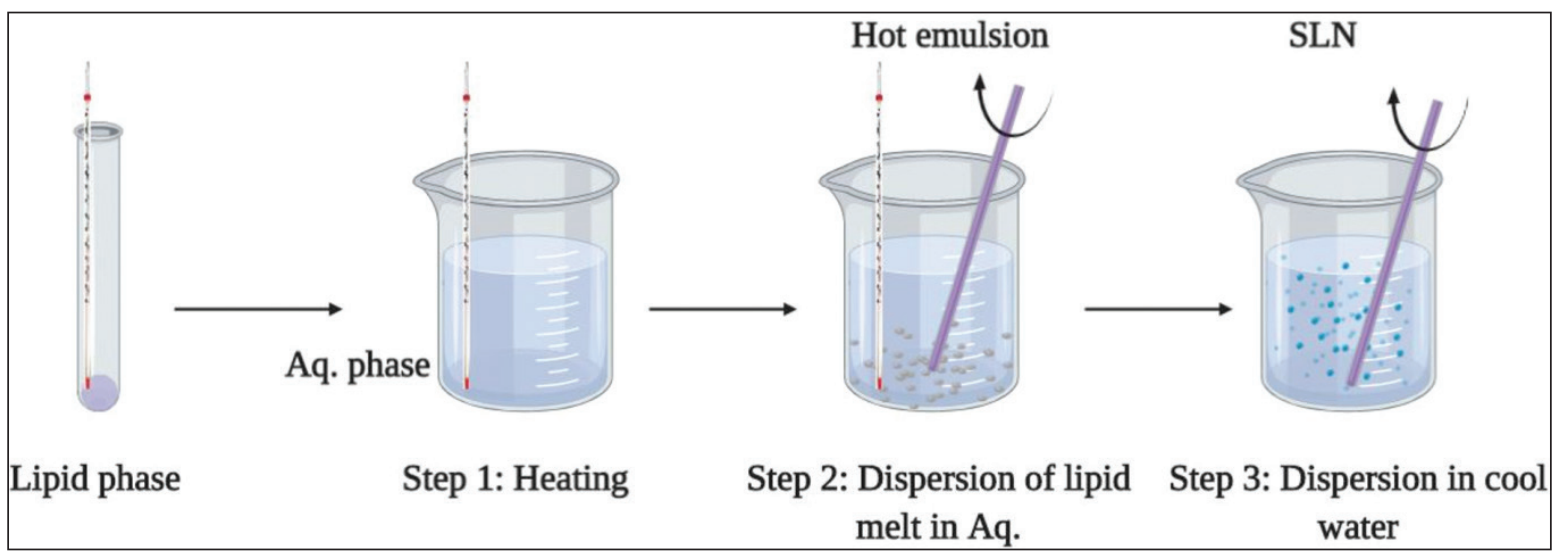

Figure 8. Microemulsion technique.

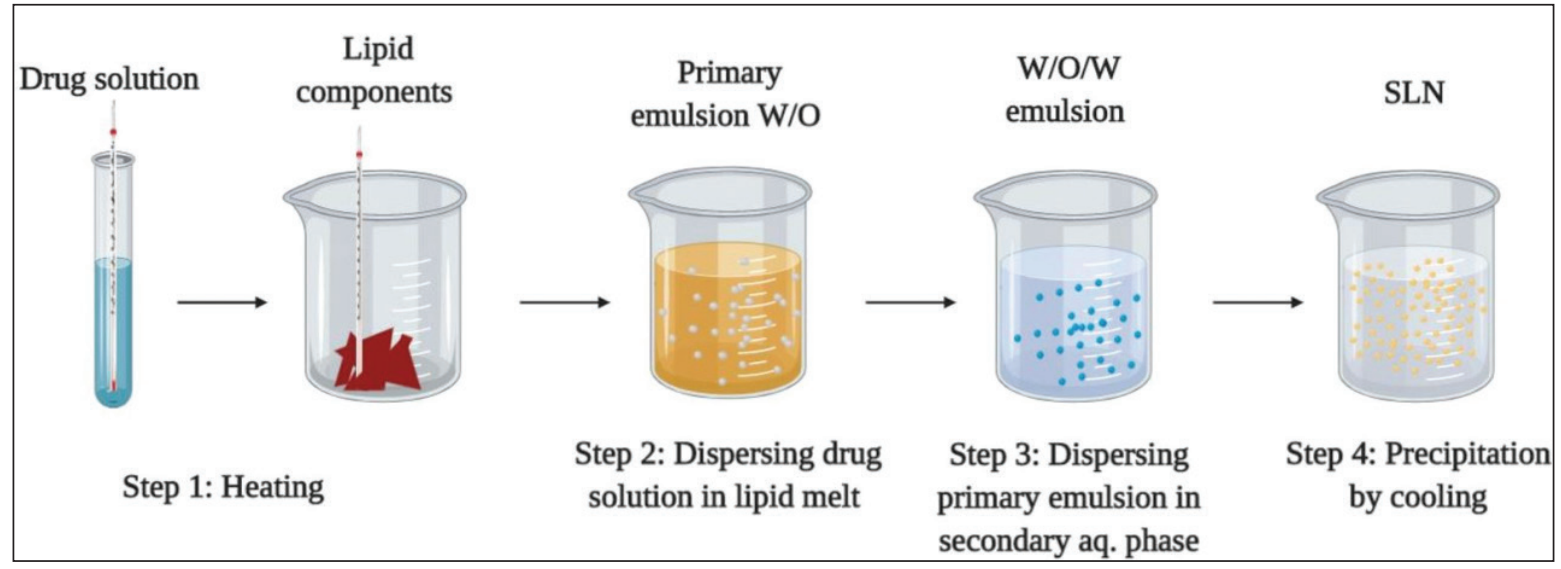

Figure 9. Double emulsion technique.

acid) (PLGA) is vital for the primary w/o emulsion emulsification process. It is observed that with the increase in the concentration of PLGA, there is an enhancement in loading capacity, w/o emulsion stability, and the encapsulation efficiency. PLGA has no impact on the SLN particle size, and with the increase in the concentration of PLGA, there is a significant decline in the zeta potential.

\section{Characterization of SLNS}

Several techniques and instruments employed for the characterization of SLNs are discussed as follows (Paurnima et al., 2018; Poovi and Damodharan, 2017).

\section{Visual size and distribution}

\section{Photon correlation spectroscopy (PCS)}

PCS measures the variations of scattered light by means of particle movement. It measures a size range of about a few nanometers to 3 microns. It depends on the diffraction angle on the particle radius (Jerome et al., 2004).

\section{Laser diffraction (LD)}

LD has a merit that it has a wide range from nanometer to lower millimeter. Polarization intensity differential scattering increased the sensitivity of LD to small particles (Mukherjee et al., 2009).

\section{Dynamic light scattering}

It records the difference in the intensity of the scattered light in the time gap of microseconds. Light is scattered under Brownian motion and quantified by the compilation of an autocorrelation function. Few presumptions such as size, low concentration, and viscosity are measured by this coefficient (Van de Ven et al., 2009).

\section{Static light scattering (SLS)}

It is also known as Fraunhofer diffraction. It is a method where the pattern of the scattered light is collected from a solution of particles and placed in an electromagnetic equation. It is a rough and quick method (Akanksha et al., 2012).

\section{Electrical surface potential and $\mathrm{pH}$}

\section{Zeta potential}

Its measurement can be analyzed using zeta potential analyzer or zetameter. Zeta potential gives information about the magnitude of the electrostatic repulsion or attraction between particles in the aqueous suspension of SLN (Mishra et al., 2012).

pH-sensitive probes

A pH probe is a scientific device that determines the $\mathrm{H}^{+}$ ion activity in hydrophilic liquids. On the basis of $\mathrm{pH}$, they give 
information about the acidity and alkalinity of the substances. The magnitude of electrochemical potential is estimated by the Nernst equation (Karmen et al., 2011).

\section{Shape and surface morphology}

\section{Transmission electron microscopy}

A high energy beam of electrons are exceled across the analyte (very fine), and thus, interactions among these electrons and the atoms can be used to perceive the features such as the crystal structure and features in the structure such as dislocations and grain boundaries (Jores et al., 2004).

\section{Scanning electron microscopy}

It produces sample images by scanning the surface with a focused beam of electrons. These electrons interact with samples and produce various signals that contain information about the surface topography and composition of the sample.

\section{Atomic force microscopy}

This involves colloidal or resistance across the sample. This movement between tip and surface is tracked by the topological map based on the forces that play. This approach helps us to obtain ultrahigh resolution by mapping the sample (Carrillo et al., 2013).

\section{Optical microscopy}

Optical microscopy also referred to as light microscopy is a type of microscope, which utilizes the light of visible range along with an arrangement of magnifying lenses to observe the small objects. This type of microscope captures the image by normal, photosensitive cameras to obtain a micrograph (Majid et al., 2019).

\section{Crystallinity}

\section{$X$-ray diffraction}

This process is used to measure the degree of crystallinity, and this is determined by the scattering of radiation from the crystal plane within a solid substance. X-ray diffraction method can be used to determine the crystallinity with a nanoparticle. This method is useful to test the bulk material (Andreas et al., 2012)

\section{Surface hydrophobicity}

Two-phase partition

This method splits the compounds in two different immiscible fluids usually polar and nonpolar, on the basis of their relative solubilities. The chemical potential aids in the separation process. The two major types are polymer/polymer and polymer/ salt systems. Some of the factors affecting the phase separation are $\mathrm{pH}$, biomolecule concentration, polymer concentration, and biomolecule's surface properties. They impart sensitive conditions that do not damage liable biomolecules (Johanna et al., 2018).

\section{Contact angle measurement}

The contact angle is the angle between soli-liquid interaction at interface or two vapors or two liquids. It is based on Young's equation. The device used to measure is goniometer. A scale of maximum contact angle to minimum contact is seen in a dynamic phenomenon of contact angle hysteresis. Contact angle has been crucial in parameter to estimate the wetting capacity of the polymer membrane surface. There are a few factors affecting the contact angle such as heterogeneity, surface roughness, and size and shape of the particle (Kai et al., 2017).

Examples of alternative instrument are radiolabel probe and synchrotron radiation X-ray (Poumellec et al., 2016).

\section{Density}

Gas pycnometer

The gas pycnometer is an apparatus used to calculate the true density of a solid material by using Archimedes principle and Boyle's law. In this instead of a fluid an inert gas is used, mostly helium is used. There are a few advantages as it gives quick with accurate results.

\section{Viscosity}

Viscometer

A viscometer is a device used to calculate the viscosity of a fluid. For fluids with changes in flow conditions, another device named rheometer is used. Viscometer can only determine under a single flow condition. Usually, either the object passes through the fluid or the liquid stays without movement or vice versa. For the condition of flow, there need to have a slight value of Reynolds' number for laminar flow. There are different types of viscometers: u-tube viscometer, falling sphere viscometer, Krebs' viscometer, quartz viscometer, etc. (Vandana and Amit, 2019).

\section{Molecular weight}

\section{Gel permeation chromatography}

It is otherwise known as size exclusive chromatography that enables separation on the basis of analyte size.

\section{In vitro release}

Membrane diffusion method is broadly used to investigate in vitro drug dissolution. The methods including dialysis sac method, reverse dialysis sac method, and side-by-side dialysis method are used, in many devices (Ghada and Rania, 2009).

Sample and separation methods are used to separate the dispersed nanoparticles from the continuous phase. Amount of drug is examined. Because of the little size of nanoparticulate systems, it is very hard to segregate them from the media (Ramteke et al., 2012)

Continuous flow methods were developed initially to alter the oral dosage release. The use of United States Pharmacopeia apparatus four method has a lot of advantages in restoring the in vitro surrounding (Junxian et al., 2009).

\section{Summarizing Studies on Lipid Nanoparticles for Their Therapeutic} Benefits

\section{Enhanced bioavailability}

Nanomedicine is a credible approach in improving the therapeutic benefit of anticancer drugs (Fan et al., 2014) 
Intravenous administration has raised difficulties for patients undergoing chemotherapy as it requires professional supervision. The major advantage of oral chemotherapy is patient compliance and flexibility in timing and ease of administration. Unfortunately, due to the rough biological conditions and poor diffusion across gastrointestinal (GI) tract, many anticancer drugs are poorly bioavailable through oral administration (Mei et al., 2013). Paclitaxel shows successful activity against breast, lung, and ovarian cancers. Cytochrome $\mathrm{P} 450$ activity and P-glycoprotein (P$\mathrm{gp})$ present in the stomach lining and liver limit the bioavailability of drug through oral route (Hendrikx et al., 2013). These difficulties in oral delivery of anticancer drugs, namely, drug-resistant tumors, toxicity, and low stability, are resolved by SLNs (Yadav et al., 2014).

Some materials may be entrapped in the external layer of SLNs to enhance the therapeutic activity of the oral delivery systems. Wheat germ agglutinin (WGA) was coated by Pooja et al. (2016) to enhance the oral paclitaxel delivery. The incorporation of paclitaxel into WGA-covered SLNs led to a fold increase in mean residence time. Baek et al. improved the surface of paclitaxel with the aid of hydroxypropyl-beta-cyclodextrin (Baek et al., 2012). The dextrin has a property to enhance the solubility and prevent the oxidation of lipids (Zafar et al., 2014).

Docetaxel is a second-generation taxane enormously used for the cure of prostate, lung, breast, and neck/head cancers. Due to poor bioavailability, the designing of oral docetaxel is hindered. Tween 80 or D-alpha-tocopherol polyethylene glycol succinate-coated SLNs were developed to boost the oral delivery of the drug (Cho et al., 2014). SLNs showed a sustained docetaxel release when set side by side with taxotere. Vorinostat is an inhibitor of histone deacetylase (HDAC) that effectively promotes apoptosis and cell cycle arrest for the cure of T-cell lymphoma (Ozaki et al., 2008). Combination of HDAC and a variety of DNA destroying agents is a favorable chemotherapeutic plan for the death of tumor cells. Hashem et al. assessed the bioavailability through oral route and cytotoxicity of SLNs enveloping tamoxifen, the drug for dealing with breast cancer (Hashem et al., 2014). The profiles for in vitro release testing gave out an instant preliminary release followed by sustained release. About a 1.6-fold increase in bioavailability was observed with SLNs administration.

Nowadays, oral SLNs are used in antitubercular therapy. Antitubercular drugs such as pyrazinamide, rifampicin, and isoniazid loaded in SLN were able to drop the dosage frequency and boost the patient compliance (Pandey et al., 2005). The mechanism for the preparation of antitubercular drug-loaded SLNs is emulsion solvent diffusion technique. These drugs enhanced bioavailability. Paclimer is a standard formulation developed to assist in maintaining progressive and systematic levels of paclitaxel (PTX) for a long duration of time. The composition constitutes of polilactofate polymer-loaded PTX, which was developed by Harper in 1999 who later tested its efficiency in the treatment of non-small-cell lung carcinoma (Jain et al., 2012). Expansile is another standard nanoparticle formulation used for lung cancer cells. This drug has a special feature of responding to the high acidic $\mathrm{pH}$ present around the cancer cells. These nanoparticles act on the acidic-hydrophobic group that causes swelling of polymeric nanoparticle and release of the payload (Zubris et al., 2012).

Disorders such as depression and anxiety which are treated by oral dose are constrained by aqueous solubility, firstpass effect, and short half-life (Jain et al., 2012). Treatment for psychotic disorders needs regular dose administration, which can lead to less patient compliance and high cost (Zubris et al., 2012). By mixing dopamine agonist, apomorphine is formed which is used in the treatment of Parkinson's disease. The quick breakdown of apomorphine in the GI tract has shown the results of $1.7 \%$ in a bioavailability (Subramony, 2006). SLNs gave the results of 13-fold higher in bioavailability than the reference solution. There are a few headache disorders such as migraines which carry symptoms of nausea, photophobia, etc. The first drug accepted by the US Food and Drug Administration was sumatriptan. Encapsulated sumatriptan chitosan-coated SLNs were used (Hansraj et al., 2015). Rizatriptan-loaded SLNs exhibited an 18-fold increase in brain uptake in rats according to an in vivo study. The first-line antidepressant venlafaxine is used for the treatment of depressive disorders and anxiety. Since venlafaxine substrate at P-gp, its penetration is reduced across GI and blood-brain barrier (Minassi et al., 2013). However, a marked increase in area under the curve (AUC) of about 1.5-fold was observed from SLNs in the brain venlafaxine solution.

For treating cardiovascular (CV)-related diseases, SLNs have been used orally, to enhance drug plasma concentration and prolong circulation duration. These features are important for attaining better therapeutic benefits. Under refrigeration at room temperature, the optimized SLNs were stable for 3 months (Hernandez et al., 2002). A 2.2-fold increase in the oral bioavailability of SLNs was given by the pharmacokinetic study as compared with nisoldipine suspension. For hypertension and heart failure remission, a prodrug of candesartan called candesartan cilexetil and an angiotensin-2 type-I receptor antagonist is employed. Using dynasan as the solid-lipid, oral bioavailability was increased more than 2.8 -fold by SLNs after inclusion of candesartan cilexetil (Dudhipala and Veerabrahma, 2016). An antihypertensive drug called carvedilol has a low oral bioavailability of $20 \%$ because of the first-pass effect. SLNs were developed with $\mathrm{N}$-carboxymethyl chitosan coating which improved oral delivery while protecting carvedilol in an acidic environment (Venishetty et al., 2012). In simulated gastric fluid, $5.2 \%$ of the drug was released by polymer-coated SLNs for 24 hours. The AUC of polymer-coated SLNs was higher than non-coated SLNs and free control. Anemia could be treated using iron supplements. However, in the GI system, these iron supplements that are commercially available can cause undesirable effects (Murioz et al., 2011). Hence, a biphasic release behavior with a burst release followed by sustained release iron-loaded SLNs is exerted. There was about a 4-fold gain in oral iron bioavailability.

Oral raloxifene has been accepted in the treatment of postmenopausal osteoporosis. Due to its poor aqueous solubility and glucuronide conjugation, thus only $2 \%$ raloxifene is orally bioavailable (Gluck and Maricic, 2003). 
Using compritol 888 ATO as the lipid and poloxamer 188 as emulsifier SLNs for raloxifene delivery was prepared $(\mathrm{Hu}$ et al., 2008). SLNs yielded a prolonged drug release for 24 hours, whereas control gave complete release within 4 hours. For the treatment of postmenopausal osteoporosis, a calciumregulating peptide hormone called salmon calcitonin secreted from the ultimobranchial gland of salmon is employed (Cheng et al., 2009). In a study, prepared SLNs exhibited effective in vivo hypercalcemic effect in rats than free calcitonin. The examination of the protective efficacy of SLNs on calcitonin opposed to pancreatin was studied. A major part of free calcitonin was broken down within 15 minutes, whereas in SLNs the rate of degradation was much slower.

SLNs were extensively used in treating infections, and they were utilized for loading antimicrobial agents to cure bacterial, parasitic, viral, and fungal infections. For example, antitubercular drug isoniazid proposed by the World Health Organization for treating all sorts of tuberculosis. A drug with a short half-life suggests the requirement for repeated dosing which leads to toxicity in the liver (Preziosi, 2007). SLNs loaded with isoniazid enhanced the bioavailability and extended circulation retention (Bhandari et al., 2013). A three-phase design was observed from the in vitro release comprising a primary rapid release, followed by a hump and eventually subsided. Miconazole is a broad-spectrum antifungal drug with poor water solubility. A loading of miconazole in SLNs exhibited a two-phase drug release with a primary outburst followed by a delayed release (Aljaeid et al., 2016). In the diffusion disk, the SLNs showed a better mortality.

Lopinavir was used in the antiretroviral treatment, a human immunodeficiency virus (HIV) protease inhibitor. Since the first-pass metabolism and P-gp efflux it, SLNs behave as a viable porter for lopinavir. Due to its particle size and release rate, the lopinavir-loaded SLNs were stable for 4 months at $4^{\circ} \mathrm{C}$ (Negi et al., 2013). When compared with the solution form of lopinavir, the SLNs gave a higher oral bioavailability because of improved lymphatic delivery. Compritol 888 was utilized as the solid-lipid for formulating lopinavir-loaded SLNs (Negi et al., 2014). Primaquine is exclusively used to prevent the relapsing form of malaria. Higher doses of primaquine conventionally lead to hematological- and GI-related toxicity (Baird, 2012). A good controllable release of the drug over 72 hours was observed by the entrapment of primaquine in SLNs (Omwoyo et al., 2014). In these days, praziquantel is used for the treatment of parasitic disease, schistosomiasis. Due to the minimal effect on schistosomiasis, De souza et al. added praziquantel into SLNs to study the improvement of therapeutic efficiency (De Souza et al., 2014). After a detailed study, it was noticed that SLNs were more efficient causing parasitic mortality in less duration when differentiated to free drug.

\section{Enhanced permeation}

The current research suggests the availability of abundant compounds obtained from natural resources for the treatment of cancer (Aljuffali et al., 2016). The anti-inflammatory, antioxidant, anti-apoptotic, vasodilating, and antimicrobial potentials of these products are responsible for their anticancer effects (Iriti et al., 2009). An innate form of Vitamin E tocotrienol has a promising anticancer activity in breast malignancy. However, oral delivery of gamma-tocotrienol is less effective (9\%) (Yap et al., 2003). To improve the permeation in the intestine, SLNs were employed as the design for gamma-tocotrienol (Abuasal et al., 2012). SLNs are used as targeted drug carriers for the cure of neoplasms. SLNs packed with drugs such as camptothecin and methotrexate have been used for targeting tumors (Ruckman et al., 2006). An anticancer drug tamoxifen has been loaded in SLNs to improve the penetrability and retentivity and also for the sustained release of the drug following IV administration in breast cancer therapy (Murthy, 2005).

\section{Enhanced cellular uptake}

Hyperglycemia, a result of diabetes, is a serious pathological condition leading to nervous system-related and CV destruction. Through the oral route, the absorption of insulin is tough because of gastric $\mathrm{pH}$ (acidic), epithelial cells of the GI tract, and various digestive enzymes (Gundogdu and Yurdasiper, 2014). After many research experiments, SLNs were found as the conveyors to guard the proteins and peptides which are known for the sensitivity toward the environmental considerations (Almeida and Souto, 2007). SLNs enveloped with stearic acidoctaarginine as a conveyor for insulin was outlined by Zhang et al. (2012). Octaarginine is a cell-permeating protein chain, which induces cellular uptake of certain drugs (Golan et al., 2016). This design expressed a remarkably enhanced hypoglycemic effect (3-fold) in rats when differentiated with nonenveloped SLNs. SLNs were designed consisting of Dynasan 114 as the lipid solid matrix for the case of insulin delivery through the oral route (Ansari et al., 2016). SLNs also expressed a greater protection of insulin from the GI environment when discerned from the solution form. SLNs enclosed with polyethylene glycol (PEG) were designed to enhance the stability of glibenclamide in gastric solution. Oral SLNs showed a rapid decrease in glucose levels and further sustained for 8 hours after administration, whereas the administration of free glibenclamide through oral route $(5 \mathrm{mg} / \mathrm{kg})$ decreased glucose levels after 4 hours, and it retained to primary high levels in diabetic rats (Goncalves et al., 2016).

\section{Reduced toxicity}

Metal nanoparticle has a cytotoxic impact on lung cells, and this is caused by the presence of metal nanoparticle in water, medicine, food, and cosmetic creams and lotions which we use on a daily basis. The size, concentration, and duration of exposure affect the level of cytotoxicity. These factors play a role in lung cancer and need to be controlled. The studies have been conducted for lung cancer therapy and diagnoses using nanoparticle. However, there has been a more extensive study with gold $(\mathrm{Au})$ nanoparticle. Annihilation of A549 lung cancer cells could be achieved using hallow Au/silver (Ag) nanostructures with dendritic morphology (Hu et al., 2008). Similarly, Au-based nanomaterials conjugated with an antibody for photothermal therapy of tumor cells have been developed. It was observed that Gold nanoparticles (Au-NPs) in conjugation 
with methotrexate, an analog of folic acid, produced a cytotoxic effect. It was observed that conventional treatment for lung cancer is costly and failed to deliver the accurate results, and hence, a need for novel technique for the diagnosis of lung cancer from Au-NP-based diagnosis from breath sample was studied (Chen et al., 2007). Principally volatile organic compound is altered in exhaled breath of person suffering from lung cancer compared to healthy individuals. Enzyme-linked immune solvent assay is less effective than hallow $\mathrm{Au}$ nanospheres in detecting lung cancer (Chon et al., 2009). Neodymium used in treatment of cancer cell belongs to group of rare earth metals. Neodymium is observed to be cytotoxic against cancer cell neodymium oxide (nano $\mathrm{Nd} 2 \mathrm{O} 3$ ), which was observed to induce vacuolization and extensive autophagy in cells by disturbing mitochondrial membrane and also arrest cycle in S phase (Chen et al., 2005).

Diamonds measuring less than $1 \mu \mathrm{m}$ are called nanodiamonds. These are carbon materials generated by events such as an explosion and meteoritic impacts. As it is not cytotoxic in lung cells, it remains harmless and biocompatible. It has numerous implementations such as tracing and tagging of cancer cells (Liu et al., 2007). These nanoparticles associate with different molecules such as DNA, proteins, chemicals, and various anticancer drugs through covalent and noncovalent bonds. Superficially reorganized carboxylated nanometer-sized diamond was evaluated and detected. There was no reduction in cell viability and change in the protein expression profile in lung cells, but they stimulated cytotoxicity. In the case of lung cancer therapy, nanodiamonds are associated covalently with PTX. During experimentation, this combination when injected into xenograft of immunodeficiency mice restricted the growth of tumor and formation of cancer cells in the lungs by instigating apoptosis and mitotic arrest (Liu et al., 2010).

Metals and their combinations have been used in the field of medicine from thousands of years. Arsenic, antimony, bismuth, gold, vanadium, iron, rhodium, titanium, gallium, and platinum are the ten most vital metals which show many anticancer activities. Transition metals can associate with many negatively charged atoms by presenting a varied number of oxidation states. For instance, a transition metal complex named cisplatin contains an ion of platinum metal in its center (Desoize, 2004). Cis-diamminedichloroplatinum (DDP, cis-platin), which is an anticancer drug, is useful for the treatment of varied types of tumors, but because of its poor cancer-specific targeting and its dangerous side effects, its use nowadays is limited. Then, in 2011, Peng et al. reported the production of biocompatible epidermal growth factor receptor (EGFR)-targeted heparin DDP nanoparticles by associating one chain variable fragment antiEGFR antibody to it as the ligand of targeting for cancer in the lungs (Peng et al., 2011). Newly, a new class of metal-established anticancer drugs of ruthenium has come out its efficiency in activity when compared to platinum and its less toxicity. Some of these drugs passed phase-1 trials (Vajpayee et al., 2011).

\section{Enhanced biocompatibility}

Engineered nanomaterials have a distinctive size, shape, charge on the surface, crystallinity, solubility, and surface coating. These features can trigger chemical state in cells to actuate a pro-oxidant condition within the cells, giving rise to disproportionate energy in the cells, causing the induct of inflammation path to the death of cells. For example, silver nanoparticles, which are round in shape, are mostly harmless to human alveolar epithelial cells, whereas wire-shaped nanoparticles exhibit vigorous cell toxicity (Stoehr et al., 2011). The cell toxicity to varied cell lines has catalyzed necrosis and apoptosis techniques, which are one after the other stimulated by modifying the structure of the membrane (Carlson, 2008). The sole limitation that holds back the substantial implementation of $\mathrm{Ag}-\mathrm{NP}$ is its deprived biocompatibility to the living conditions. Altering organically by covering the Ag-NP with latex from stems of Euphorbia nivulia, a medicinal plant showed a remarkable enhancement in the biocompatibility of silver nanoparticles. These nanoparticles are cytotoxic against human lung carcinoma cell (A549) condition on dose (Valodkar et al., 2011). Latexcovered nanoparticles are produced from the terpenoid and peptide portions of the latex, which cross the membrane of the cell and can be employed as a biocompatible transporter for the NP.

Polymeric micelles are immensely confederated nanoplatforms for targeting cancer, distribution of the drug, and cancer imaging. Supermagnetic iron oxide is extensively used as a contrasting agent, which enhances the visibility of blood vessels. A multifunctional micelle (MFM) system is converted into code along with a lung cancer-targeting peptide and enfolded with superparamagnetic iron oxide and doxorubicin for MR imaging and therapeutic delivery. When compared to a scrambled peptidecoded MFM, LCP-coded MFM exhibited remarkably upgraded alpha, beta-based cell targeting in H2009 lung cancer cells (Guthi et al., 2010). An aqueous soluble and biocompatible theranostic anticancer drug transporter has been developed by conjoining fluorescent polymer chain and folic acid along with magnetic iron oxide or silica. Folic acid that is added helps for targeted drug delivery, and the fluorescent agent helps in imaging the target (Chen et al., 2010).

Bionanoparticle approaches are the major research in metal-based nanotherapeutics, but in the case of in-vivo studies, their biocompatibility and toxicity are major concerns to be noted. Hence, to control the above-mentioned problems, the present researchers have diverted their concentration on the bionanotechnology-based therapeutic component. In this development, an already existing biological system is selected and is incorporated with therapeutic nanoparticles. This incorporation with biological components improved the stability and biocompatibility of the overall system. The examples for this type of systems are models with carrier molecules such as albumin nanoparticles or ABI-007 or hematoporphyrin-linked albumin nanoparticles with therapeutic components such as paclitaxel or gamma-emitting nuclides or carboplatin (Green et al., 2006; Ibrahim et al., 2002). Table 1 shows further research findings of SLN formulations reported by researchers. Tables 2 and 3 show the patents and clinical trials of various lipid systems in recent times, respectively. 
Table 1. Research findings of SLNs formulations reported by researchers.

\begin{tabular}{|c|c|c|c|}
\hline Therapeutic agent & Formulation components & Preparation methods & References \\
\hline $\begin{array}{l}\text { Chitosan-Shea butter SLNs } \\
\text { (C-SLNs) }\end{array}$ & $\begin{array}{l}\text { Curcumin, Phospholipids/ Tween } 80 \text { stabilised shea butter SLNs, } \\
\text { Chitosan microparticles (CS-C-SLNs), Sodium tripolyphosphate (TPP) }\end{array}$ & $\begin{array}{l}\text { High shear homogenization-- } \\
\text { ultrasonication }\end{array}$ & (Hassan et al., 2018) \\
\hline $\begin{array}{l}\text { SLNs loaded with Simvastatin } \\
\text { (SIM-SLNs) }\end{array}$ & $\begin{array}{l}\text { Solid lipids glyceryl behenate, Glyceryl palmitosterate containing } \\
\text { Tween } 80 \text { as surfactant }\end{array}$ & Nanotemplate engineering & (Rizvi et al., 2019) \\
\hline Piroxicam loaded SLNs & $\begin{array}{l}\text { Piroxicam, Tripamitin lipid, Polyvinyl alcohol (PVAL) stabilizer, } \\
\text { Ethyl acetate solvent }\end{array}$ & $\begin{array}{l}\text { Solvent emulsification/ } \\
\text { Evaporation method }\end{array}$ & (Soliman et al., 2018) \\
\hline $\begin{array}{l}\text { Ibuprofen loaded SLMs } \\
\text { (Microparticles) }\end{array}$ & Ibuprofen with Glyceryl behenate, Tripalmitin, Beeswax & Emulsion congealing & (Long et al., 2006) \\
\hline $\begin{array}{l}\text { Itraconazole (ITZ) } \\
\text { (Intravenous formulation) }\end{array}$ & ITZ, Tristearin, Triolein, EggPC, Tween 80, DSPE-PEG 2000 & $\mathrm{HPH}$ & (Jin et al., 2010; Kang et al., 2018) \\
\hline $\begin{array}{l}\text { Pterodon pubescens } \\
\text { fruit oil NLCs }\end{array}$ & $\begin{array}{l}\text { Precirol } ® \text { ATO } 5,0.5 \% \text { Phospholipon } ® 80 \mathrm{H}, \mathrm{PEG}-40 \text { hydrogenated } \\
\text { castor oil/ sorbitan oleate }\end{array}$ & Melt emulsification & (Outuki et al., 2018) \\
\hline $\begin{array}{l}\text { Candesartan Cilexetil-(CDC) } \\
\text { SLNs }\end{array}$ & CDC, Stearic acid, Poloxamer 188, Dialysis membranes-70 & Emulsification-Ultrasonication & (Arjun and Kishan, 2013) \\
\hline $\begin{array}{l}\text { [6]-shogaol- loaded liposomes } \\
\text { (6-SRGO-LLPS) }\end{array}$ & $\begin{array}{l}\text { Carrier 1,2-Dimyristoylsn- glycero-3-phospho-rac- glycerol } \\
\text { (used to produce liposomes), sodium salt, (DMPG-Na) lipid, 6-shogaol, }\end{array}$ & HPH & (Wang et al., 2018) \\
\hline $\begin{array}{l}\text { Trehalose monooleate } \\
\text { SLNs for Cyclosporin-A } \\
\text { topic release }\end{array}$ & $\begin{array}{l}\text { Dichloromethane (DCM), chloroform, n-hexane, concentrated } \\
\text { sulfuric acid, 1-butanol and methanol, trehalose, Oleic acid, } \\
\text { Dicyclohexylcarbodiimide, DCC, DMAP, Dimethylaminopyridine, } \\
\text { Polyoxyehylene sorbital monolaurate(Tween 20), Biliary acid, } \\
\text { Coumarin-6, Cyclosporin-A, Methylparaben, Propylparaben }\end{array}$ & Microemulsion & (Sonia et al., 2019) \\
\hline $\begin{array}{l}\text { Glutathione loaded SLNs } \\
\text { (GSH-SLNs) }\end{array}$ & $\begin{array}{l}\text { Gelucire } \mathbb{R} \text { 50/13, L-Glutathione reduced (GSH), Tween } 85 \text {, acetic } \\
\text { acid, 2,2-diphenyl-1-picrylhydrazyl (DPPH), cetyltrimethylammonium } \\
\text { bromide, 3,3',5,5'- tetramethylbenzidine hydrochloride (TMB) } \\
\text { phorbol myristate acetate (PMA), fluorescein isothiocyanate (FITC) } \\
\text { and luminol, Penicillin and streptomycin, RPMI-1640 culture } \\
\text { medium and foetal calf serum (FCS) }\end{array}$ & $\begin{array}{l}\text { X-ray photoelectron } \\
\text { spectroscopy analysis (XPS) }\end{array}$ & (Adriana et al., 2018) \\
\hline Cloithronycin & Liquid matrix, Glyceryl behenate, Tripalmitin and stearic acid. & $\begin{array}{l}\text { High speed homogenization } \\
\text { technique. }\end{array}$ & (Alper et al., 2019) \\
\hline Seabuckthorn & Probiotic, Lactobacillus acidophitus, Bifidobacterium lactis, TTA. & Microwave extraction. & (Aynur et al., 2016) \\
\hline $\begin{array}{l}\text { Clotrimazole loaded SLN } \\
\text { and NLC }\end{array}$ & $\begin{array}{l}\text { Cetostearyl alcohol, Cetyl esters wax, 2-octydodecanol, polysorbate } 60 \text {, } \\
\text { Sorbitan monostearate, Benzyl alcohol, purified water. }\end{array}$ & $\begin{array}{l}\text { Hot high-pressure homogenization } \\
\text { technique. }\end{array}$ & (Souto et al., 2004) \\
\hline Cholesteryl butyrate SLN & Cholesterol, Cholesteryl, Acetonitrile, Chloroform, methanol (1:1:1 v/v) & Microemulsion formulation & (Elena et al., 2001) \\
\hline Polyhydroxy surfactants & Non-ionic ethylene oxide & Hot high-pressure homogenization & (Andjelka et al., 2014) \\
\hline Doxorubian & Adriomycin & $\begin{array}{l}\text { Small angle neutron scattering } \\
\text { (SANS), small angle X-ray } \\
\text { scattering (SAXS). }\end{array}$ & (Fabiano et al., 2018) \\
\hline Lopinvir (Lo) SLN & Lopinavir and ritnavir & $\begin{array}{l}\text { Hot homogenization, } \\
\text { ultrasonication. }\end{array}$ & (Aji et al., 2011) \\
\hline Tretinain (TRE) SLN & $\begin{array}{l}\text { Steric acid, Isopropyl, Myristate, Polyoxyl } 40 \text { stearate, Xanthan gum, } \\
\text { Sorbic acid, Butylated Hydroxytoluene. }\end{array}$ & $\begin{array}{l}\text { Simple emulsion solvent diffusion } \\
\text { (ESD) technique }\end{array}$ & (Shah et al., 2007) \\
\hline $\begin{array}{l}\text { Fenfitrate and } \\
\text { Nabumetone SLN }\end{array}$ & $\begin{array}{l}\text { Hypromellose, Polyethylene glycol, Polysorbate } 80 \text {, SLS, } \\
\text { Microcrystalline cellulose, Titanium dioxide. }\end{array}$ & Hot melt homogenization. & (Raj et al., 2020) \\
\hline Ascorbic acid & Vitamin C complex, Ascorbic acid, Volatile acid & Hot homogenization & (Gamze et al., 2014) \\
\hline Trans- Ferulic acid (TFA) & Ethyl oleate, Glyceryl behenate. & Microemulsion & (Zhang et al., 2016) \\
\hline Rivastigmine (RHT) SLN & $\begin{array}{l}\text { Hydroxypropyl methylcellulose, Magnesium state, Microcrystalline } \\
\text { cellulose, Silicon dioxide, Compritol } 888 \text { ATO, Poloxamer } 188\end{array}$ & Ultrasonication, Homogenization. & (Brijesh et al., 2015) \\
\hline$\alpha$ Bisabolol SLN & Sterols, Triterpenes, Volatiles, Polar and other constituents. & Hot homogenization & (Sethuraman et al., 2018) \\
\hline
\end{tabular}


Table 2. List of patents published for various lipid systems.

\begin{tabular}{|c|c|c|c|}
\hline Application number & Publication date & Title & Applicants \\
\hline PCT/IB2018/001073 & 19.03.2020 & $\begin{array}{l}\text { Mucoadhesive dispersion nanoparticle system and method for production } \\
\text { the same }\end{array}$ & Lead Biotherapeutics Ltd. [bg/bg]; bg \\
\hline 201833026370 & 17.01 .2020 & $\begin{array}{l}\text { An improved acyclovir loaded solid lipid nanoparticulate gel formulation } \\
\text { for topical application and method of formulating the same }\end{array}$ & $\begin{array}{l}\text { Subhabtota, Majumdar, Samir kumar, } \\
\text { Samanta, Suvalaxmi sarkar }\end{array}$ \\
\hline 201831016759 & 08.11 .2019 & Nanoparticle for targeted oral chemotherapy & Chakrabarti, gopal \\
\hline 201822045013 & 27.09.2019 & Multilayer coating & Meril Life Sciences Pvt Ltd \\
\hline PCT/IN2018/050300 & 26.09.2019 & Drug-coated balloon & $\begin{array}{l}\text { Meril Life Sciences Pvt Ltd [in/in]; bilakhia house } \\
\text { muktanand marg, chala, vapi, gujarat vapi 396191, in }\end{array}$ \\
\hline 201910404515.0 & 06.08 .2019 & Preparation method of chlorogenic acid lipid nanoparticle solid dispersion & Bengbu University \\
\hline 16377032 & 01.08 .2019 & Compositions and methods for nanoparticle lyophile forms & Nitto Denko Corporation \\
\hline PCT/IB2017/001582 & 20.06 .2019 & $\begin{array}{l}\text { Solid lipid nanoparticle for intracellular release of active substances and } \\
\text { method for production the same }\end{array}$ & Lead Biotherapeutics Ltd. [bg/bg]; bg \\
\hline 16263769 & 06.06 .2019 & Fluorescent solid lipid nanoparticles composition and preparation thereof & Bracco Imaging S.p.A. \\
\hline 201910182104.1 & 28.05.2019 & $\begin{array}{l}\text { Preparation method and application of resveratrol-solid solid lipid } \\
\text { nanoparticle }\end{array}$ & Bengbu Medical College \\
\hline 1020170144092 & 09.05.2019 & $\begin{array}{l}\text { Composition for preventing or treating xeroderma containing phragmites } \\
\text { communis root extract and serine-loaded solid lipid nanoparticles as active } \\
\text { components }\end{array}$ & Erom Co., Ltd. \\
\hline 201811397576.0 & 09.04.2019 & $\begin{array}{l}\text { Ampelopsin grossedentata total flavonoid solid lipid nanoparticles and } \\
\text { preparation method }\end{array}$ & Fujian University of Traditional Chinese Medicine \\
\hline 201811110809.4 & 08.03 .2019 & $\begin{array}{l}\text { Construction method and application of nano drug loading system targeting } \\
\text { cell endoplasmic reticulum }\end{array}$ & Zhejiang University \\
\hline 201711028760 & 01.03 .2019 & Topical nanoformulation of tetrahydrocurcumin (thc) & University Institute of Pharmaceutical Sciences \\
\hline 201810924463.5 & 04.01 .2019 & $\begin{array}{l}\text { Carvacrol solid lipid nanoparticles dispersion liquid with bacteriostatic } \\
\text { activity, preparation method and application thereof }\end{array}$ & Wuhan Polytechnic University \\
\hline 201721010354 & 28.09 .2018 & $\begin{array}{l}\text { SLNs composition comprising metformin and pomegranate peel extract } \\
\text { for the treatment of diabetes mellitus type II. }\end{array}$ & M.C.E.Society's Allana College of Pharmacy \\
\hline 201721010355 & 28.09.2018 & $\begin{array}{l}\text { SLNs composition comprising fenofibrate and pomegranate peel extract } \\
\text { for the treatment of hyperlipidaemia. }\end{array}$ & M.C.E.Society's Allana College of Pharmacy \\
\hline 201810366608.4 & 21.09 .2018 & $\begin{array}{l}\text { Local analgesic microneedle device for neuropathic pain and preparation } \\
\text { method thereof }\end{array}$ & Sun Yat-sen University \\
\hline 201810266539.X & 21.08.2018 & $\begin{array}{l}\text { Sports fatigue-resistant resveratrol solid lipid nanoparticles and preparation } \\
\text { method thereof }\end{array}$ & Tongji University \\
\hline 201810042421.9 & 10.08.2018 & $\begin{array}{l}\text { Cyclosporin solid lipid nanoparticles with good storage physical stability } \\
\text { and preparation method thereof }\end{array}$ & Nanchang University \\
\hline
\end{tabular}

WIPO - Search International and National Patent Collections (2020).

Table 3. List of clinical trials being carried in for lipid systems for various disease types.

\begin{tabular}{|c|c|c|c|c|c|c|}
\hline Agent and trial no. & Trial type & Disease type & Title & Status & Phase & Study completion date \\
\hline NCT03323398 & $\begin{array}{l}\text { Interventional } \\
\text { (Clinical trial) }\end{array}$ & Advanced malignancies & $\begin{array}{l}\text { Dose Escalation and Efficacy Study of mRNA } 2416 \text { for } \\
\text { Intratumoral Injection Alone and in Combination with } \\
\text { Durvalumab for Patients With Advanced Malignancies }\end{array}$ & Recruiting & Phase 2 & March 2022 \\
\hline NCT04213937 & $\begin{array}{l}\text { Interventional } \\
\text { (Clinical Trial) }\end{array}$ & $\begin{array}{l}\text { Extensive Stage Small } \\
\text { Cell lung cancer }\end{array}$ & $\begin{array}{l}\text { The Efficacy and Safety of Nab-paclitaxel Versus } \\
\text { Topotecan As Second-Line Treatment for Patients with } \\
\text { Extensive Stage Small Cell Lung Cancer: A Multicentre, } \\
\text { Randomized Controlled Study }\end{array}$ & Recruiting & Phase 2 & January 31,2022 \\
\hline NCT04183257 & $\begin{array}{l}\text { Interventional } \\
\text { (Clinical Trial) }\end{array}$ & $\begin{array}{l}\text { Vitamin D Deficient } \\
\text { Type } 2 \text { Diabetes }\end{array}$ & $\begin{array}{l}\text { Effect of Escalating Oral Vitamin D Replacement on } \\
\text { HOMA-IR in Vitamin D Deficient Type } 2 \text { Diabetics }\end{array}$ & Completed & Phase 4 & July 30, 2017 \\
\hline NCT03352843 & $\begin{array}{l}\text { Interventional } \\
\text { (Clinical Trial) }\end{array}$ & Malaria & $\begin{array}{l}\text { Single Low-dose Primaquine Efficacy and Safety for } \\
\text { Treatment of Uncomplicated Plasmodium Falciparum } \\
\text { Malaria Based on Cytochrome P450 2D6 Activity }\end{array}$ & Recruiting & Phase 4 & November 30, 2020 \\
\hline NCT03314064 & $\begin{array}{l}\text { Interventional } \\
\text { (Clinical Trial) }\end{array}$ & Infection, HIV & $\begin{array}{l}\text { Long-term Safety of Subjects Continuing Dolutegravir } \\
\text { After Participation in Clinical Studies of Dolutegravir } \\
\text { in Russian Federation }\end{array}$ & Completed & Phase 4 & October 1,2018 \\
\hline NCT03199560 & $\begin{array}{l}\text { Interventional } \\
\text { (Clinical Trial) }\end{array}$ & Sentinel lymph node biopsy & $\begin{array}{l}\text { Tilmanocept } v s \text {. Sulfur colloid in Sentinel lymph node } \\
\text { biopsy }\end{array}$ & Recruiting & Phase 4 & August 22,2019 \\
\hline NCT04186377 & $\begin{array}{l}\text { Interventional } \\
\text { (Clinical Trial) }\end{array}$ & Diabetic Foot Ulcer Healing & $\begin{array}{l}\text { A Study of the Effectiveness of Local S26E Extract } \\
\text { Application for Diabetic Foot Ulcer Healing }\end{array}$ & Recruiting & Phase 2 & November 29, 2021 \\
\hline
\end{tabular}




\begin{tabular}{|c|c|c|c|c|c|c|}
\hline Agent and trial no. & Trial type & Disease type & Title & Status & Phase & Study completion date \\
\hline NCT04213170 & $\begin{array}{l}\text { Interventional } \\
\text { (Clinical Trial) }\end{array}$ & Lung Cancer & $\begin{array}{l}\text { Sintilimab Combined With Bevacizumab for Driving } \\
\text { Gene-negative, Asymptomatic Brain Metastases From } \\
\text { Non-small Cell Lung Cancer }\end{array}$ & Recruiting & Phase 2 & December 2022 \\
\hline NCT04085419 & $\begin{array}{l}\text { Interventional } \\
\text { (Clinical Trial) }\end{array}$ & Primary Hyperparathyroidism & $\begin{array}{l}\text { Management of Osteoporosis in Patients With Primary } \\
\text { Hyperparathyroidism }\end{array}$ & Recruiting & Phase 4 & May 2022 \\
\hline NCT04206865 & $\begin{array}{l}\text { Interventional } \\
\text { (Clinical Trial) }\end{array}$ & $\begin{array}{l}\text { Decompensated Heart Failure } \\
\text { and Low Cardiac Output }\end{array}$ & $\begin{array}{l}\text { Comparison of ARNI to Alternate Oral Vasodilator } \\
\text { Therapies to Determine the Hemodynamic Profile } \\
\text { and Relative Tolerability of (ARNIs) in Patients with } \\
\text { Decompensated Heart Failure and Low Cardiac Output }\end{array}$ & Recruiting & Phase 4 & March 31, 2022 \\
\hline
\end{tabular}

Home - ClinicalTrials.Gov (2009).

\section{CONCLUSION}

SLNs have radically gained the attention of several researchers with its exceptional properties and benefits over other conventional dosage forms, and other colloidal counterparts of SLN have proved to be a significant discovery in nanotechnology because of their effective performance and as a safe vehicle in pharmaceutical drug delivery. SLN as a colloidal drug carrier puts together the advantages of polymeric nanoparticles and fatbased emulsions. These systems abet various benefits such as easy incorporation of lipid- and water-soluble drugs, adequate physical stability, and available at low cost and easy to manufacture. Their inherent characteristics qualify SLNs as competent nanocarriers in the expansion of targeted delivery systems for the clinical trial investigations. Similarly, SLNs also favor sustained release besides effective drug targeting.

\section{AUTHORS' CONTRIBUTION}

All the authors were equally contributed to the data collection, information, writing, and critical review helped design for a framework of the document.

\section{CONFLICT OF INTEREST}

The authors report no conflict of interest.

\section{FUNDING}

None.

\section{REFERENCES}

Abuasal BS, Lucas C, Peyton B, Alayoubi A, Nazzal S, Sylvester PW, Kaddoumi A. Enhancement of intestinal permeability utilizing solid lipid nanoparticles increases gamma-tocotrienol oral bioavailability. Lipids, 2012; 47:461-9.

Adriana T, Giuseppe T, Delia M, Nicola C, Nicoletta D, Vincenzo DL, Hector C, Maria AE. Glutathione-loaded solid lipid nanoparticles based on Gelucire ${ }^{\circledR}$ 50/13: spectroscopic characterization and interactions with fish cells. J Drug Delivery Sci Technol, 2018; 47:359-66.

Aji AMR, Chacuko AJ, Jose S, Souto EB. Lopinavir loaded solid lipid nanoparticles for intestinal lymphatic targeting. Eur J Pharm Sci, 2011; $1: 11-8$.

Akanksha G, Deepti S, Navneet G. Solid lipid nanoparticles method, characterization and applications. Int Curr Pharm J, 2012; 1:384 93.

Aleksandra Z, Carlos M, Nuno R, Silva AM, Nowak I, Souto EB. Anti-inflammatory and anti-cancer activity of citral: optimization of citral-loaded solid lipid nanoparticles (SLN) using experimental factorial design and LUMiSizer ${ }^{\circledR}$. Int J Pharm, 2018; 553:428-40.

Alessi P, Cortesi A, De Zordi N, Gamse T, Kikic I, Moneghini M. Supercritical antisolvent precipitation of quercetin systems: preliminary experiments. Chem Biochem Eng Q, 2012; 26:391-8.
Aljaeid BM, Hosny KM. Miconazole-loaded solid lipid nanoparticles: formulation and evaluation of a novel formula with high bioavailability and antifungal activity. Int J Nanomed, 2016; 11:7-441.

Aljuffali IA, Fang CL, Chen CH, Fang JY. Nanomedicine as a strategy for natural compound delivery to prevent and treat cancers. Curr Pharm Design, 2016; 22:4219-31

Almeida AJ, Souto E. Solid lipid nanoparticles as a drug delivery system for peptides and proteins. Adv Drug Deliv Rev, 2007; 59:90-478.

Alper OA, Abdurrahman A, Behiye S. Influence of glyceryl behenate, tripalmitin and stearic acid on the properties of clarithromycin incorporated solid lipid nanoparticles: formulation, characterization, antibacterial activity and cytotoxicity. J Drug Delivery Sci Technol, 2019; 54:101-240.

Andjelka BK, Rainer HM, Snezana DS, Gordana MV, Cornelia MK. Solid lipid nanoparticle stabilized with polyhydroxy surfactants: preparation, characterization and physical stability investigation. Colloids Surf A, 2014; 5:15-25.

Andreas N, Hauseb G, Mäder K. Physicochemical characterization of curcuminoid-loaded solid lipid nanoparticles. Int $\mathrm{J}$ Pharm, 2012; 423:440-51.

Ansari MJ, Anwar MK, Jamil S, Al-Shdefat R, Ali BE, Ahmad MM, Ansari MN. Enhanced oral bioavailability of insulin-loaded solid lipid nanoparticles: pharmacokinetic bioavailability of insulin-loaded solid lipid nanoparticles in diabetic rats. Drug Deliv, 2016; 23:9-1972.

Arjun N, Kishan V. Preparation, characterization and evaluation of quetiapine fumarate solid lipid nanoparticles to improve the oral bioavailability. J Pharm, 2013; 2013:1-7.

Aynur G, Christina K, Candace L, Hannah M, Jenney R, Farah $\mathrm{H}$. Seabuckthorn as a novel prebiotic source improves probiotic viability in yogurt. LWT- Food Sci Technol, 2016; 66:490-5.

Baek JS, So JW, Shin SC, Cho CW. Solid lipid nanoparticles of paclitaxel strengthened by hydroxypropyl-beta-cyclodextrin as an oral delivery system. Int J Mol Med, 2012; 30:953-9.

Baird JK. Primaquine toxicity forestalls effective therapeutic management of the endemic malarias. Int J Parasitol, 2012; 42:54-1049.

Bhandari R, Kaur IP. Pharmacokinetics, tissue distribution and relative bioavailability of isoniazid-solid lipid nanoparticles. Int J Pharm, 2013; 441:12-202.

Brijesh S, Dignesh K, Himanshu B, Manju M, Harish P. Application of quality by design approach for intranasal delivery of rivastigmine loaded solid lipid nanoparticles: effect on formulation and characterization parameters. Eur J Pharm Sci, 2015; 78:54-66.

Carlson C, Hussain SM, Schrand AM, Braydich SLK, Hess KL, Jones RL, Schlager JJ. Unique cellular interaction of silver nanoparticles: size-dependent generation of reactive oxygen species. J Phys Chem B, 2008; 112:13608-19.

Carrillo C, Sanchez HN, Garcia ME, Perez LP, Sune NJM, Tico JR, Suñé C, Miñarro M. DNA delivery via cationic solid lipid nanoparticles (SLNs). Eur J Pharm Sci, 2013; 2:65-157.

Chen D, Jiang M, Li N, Gu H, Xu Q, Ge J, Xia X, Lu J. Modification of magnetic silica/iron oxide nanocomposites with fluorescent polymethacrylic acid for cancer targeting and drug delivery. J Mater Chem, $2010 ; 20: 6422-9$. 
Chen Y, Yang L, Feng C, Wen LP. Nano neodymium oxide induces massive vacuolization and autophagic cell death in non-small cell lung cancer NCI-H460 cells. Biochem Biophys Res Commun, 2005; 337:52-60.

Chen YJ, Jin RX, Zhou YQ, Zeng J, Zhang H, Feng QR. Preparation of solid lipid nanoparticles loaded with Xionggui powdersupercritical carbon dioxide fluid extraction and their evaluation in vitro release. Zhongguo Zhong Yao Za Zhi, 2006; 31:376-9.

Chen, Y, Tsai, C, Huang, P, Chang, MY, Cheng, PC, Chou, CH, Chen, H, Wang, CR, Shiau, AL, Wu, CL. Methotrexate conjugated to gold nanoparticles inhibits tumor growth in a syngeneic lung tumor model. Mol Pharmacol, 2007; 4:713-22.

Cheng, FY, Chen, CT, Yeh. CS. Comparative efficiencies of photothermal destruction of malignant cells using antibody-coated silica@Au nanoshells, hollow $\mathrm{Au} / \mathrm{Ag}$ nanospheres and $\mathrm{Au}$ nanorods. Nanotechnology, 2009; 20:425104.

Cho HJ, Park JW, Yoon IS, Kim DD. Surface-modified solid lipid nanoparticle for oral delivery of docetaxel: enhanced intestinal absorption and lymphatic uptake. Int J Nanomed, 2014; 9:495-504.

Chon, H, Lee, S, Son, SW, Oh, CH, Choo, J. Highly sensitive immunoassay of lung cancer marker carcinoembryonic antigen using surface-enhanced Raman scattering of hollow gold nanospheres. Anal Chem, 2009; 81:3029-34.

Das S, Chaudhury A. Recent advances in lipid nanoparticle formulations with solid matrix for oral drug delivery. AAPS PharmSciTech, $2011 ; 12: 62-76$

Desoize B. Metals and metal compounds in cancer treatment. Anticancer Res, 2004; 24:1529-44.

De Souza AL, Andreani T, deOliveira RN, Kiill CP, dosSantos FK, Allegretti SM, Chaud MV, Souto EB, Silva AM, Gremião MP. In vitro evaluation of permeation, toxicity and effect of praziquantel-loaded solid lipid nanoparticles against Schistosoma mansoni as a strategy to improve efficacy of the schistosomiasis treatment. Int J Pharm, 2014; 463:7-31.

Dudhipala N, Veerabrahma K. Candesartan cilexetil loaded solid liquid nanoparticle for oral delivery: characterization, pharmacokinetic and pharmacodynamic evaluation. Drug Deliv, 2016; 23:395-4045.

Eldem T, Speiser P, Hincal A. Optimization of spray-dried and congealed lipid microparticles and characterization of their surface morphology by scanning electron microscopy. Pharm Res, 1991; 8:47-54.

Elena U, Emilio M, Cinizia P, Danila C, Elena P, Maria GD, Maria RG. The effect of formulation and concentration of cholesteryl butyrate solid lipid nanoparticle on NIH-H460 cell proliferation. Eur J Pharm Biopharm, 2001; 2:197-202.

Fabiano Y, Christian S, Joachim S, Mont KV, Daniel C, Ben K, Daniel C, Friedrich W, Margareth KKDF. Effects of doxorubicin on the structural and morphological characterization of solid lipid nanoparticles (SLN) using small angle neutron scattering (SANS) and small angle X-ray scattering (SAXS). Phys B, 2018; 551:191-6.

Fan Z, Fu PP, Yu H, Ray PC. Theranostic nanomedicine for cancer detection and treatment. J Food Drug Anal, 2014; 22:3-17.

Freitas C, Muller RH. Spray-drying of solid lipid nanoparticles. Eur J Pharma Biopharm, 1998; 46:145-51.

Gamze G, Mehatap K, Lutifi G. Preparation and characterization of ascorbic acid loaded solid lipid nanoparticles and investigation of their apoptotic effects. Colloids Surf B, 2014; 121:270-80.

Garces A, Amaral M, Silva A. Formulations based on solid lipid nanoparticles and nanostructured lipid carriers for cutaneous use. Eur J Pharm Sci, 2018; 112:157-67.

Gasco MR. Solid lipid nanospheres from warm microemulsions. Pharm Tech Eur, 1997; 9:52-8.

Ghada A, Rania HF. Diazepam-loaded solid lipid nanoparticles: design and characterization. AAPS PharmSciTech, 2009; 1:211-9.

Gluck O, Maricic M. Skeletal and nonskeletal effects of raloxifene. Curr Osteoporos Rep, 2003; 1:123-8.
Golan M, Feinshtein V, David A. Conjugates of HA2 with octaarginine-grafted HPMA copolymer offer effective siRNA delivery and gene silencing in cancer cells. Eur J Pharm Biopharm, 2016; 109:103-12.

Goncalves LM, Maestrelli F, Di Cesare Mannelli L, Ghelardini C, Almeida AJ, Mura P. Development of solid lipid nanoparticles as carriers for improving oral bioavailability of glibenclamide. Eur J Pharm Biopharm, 2016; 102:41-50.

Green MR, Manikhas GM, Orlov S, Afanasyev B, Makhson AM, Bhar P, Hawkins MJ. Abraxane, a novel cremophor-free, albuminbound particle form of paclitaxel for the treatment of advanced non-smallcell lung cancer. Ann Oncol, 2006; 17:1263-8.

Gundogdu E, Yurdasiper A. Drug transport mechanism of oral antidiabetic nanomedicines. Int J Endocrinol Metab, 2014; 12:e2847.

Guthi JS, Yang SG, Huang G, Li S, Khemtong C, Kessinger CW, Peyton M, Minna JD, Brown KC, Gao J. MRI-visible micellar nanomedicine for targeted drug delivery to lung cancer cells. Mol Pharm, 2010; 7:32-40.

Hadis R, Seid RF, Seid MJ. Nanoencapsulation of carotenoids within lipid-based nanocarriers. J Control Release, 2019; 298:38-67.

Hansraj GP, Singh SK, Kumar P. Sumatriptan succinate loaded chitosan solid liquid nanoparticles for enhanced anti-migraine potential. Int J Biol Macromal, 2015; 81:467-76.

Harde H, Das M, Jain S. Solid lipid nanoparticles: an oral bioavailability enhancer vehicle. Expert Opin Drug Deliv, 2011; 8:1407-24

Hashem FM, Nasr M, Khairy A. In vitro cytotoxicity and bioavailability of solid lipid nanoparticles containing tamoxifen citrate Pharm Dev Technol, 2014; 19:824-32.

Hassan HA, Florentin M, Aya NK, Jordane J, Michel L. Chitosan - Shea butter solid nanoparticles assemblies for the preparation of a novel nanoparticles in microparticles system containing curcumin. Colloids Surf A, 2018; 553:359-67.

He H, Wang P, Cai C, Yang R, Tang X. VB12-coated Gel-CoreSLN containing insulin: another way to improve oral absorption. Int $\mathrm{J}$ Pharm, 2015; 493:451-9.

Hendrikx JJ, Lagas JS, Rosing H, Schellens JH, Bejinen JH, Schinkel AH. P-glycoprotein and cytochrome P450 3A act together in restricting the oral bioavailability of paclitaxel. Int J Cancer, 2013; 132:2439-47.

Hernandez HR, Coll T, Rachitzky P, Arrnas HM, Armas PMC, Velasco M, Rizzo A. Comparison of two nimodipine formulations in healthy volunteers. J Hum Hypertens, 2002; 16:142-4.

Home - ClinicalTrials.Gov. Available via https://clinicaltrials. gov/ (Accessed 15 April 2020).

Hu KW, Huang CC, Hwu JR, Su WC, Shieh DB, Yeh CS. A new photothermal therapeutic agent: core-free nanostructured $\mathrm{Au}$ x Ag1-x dendrites. Chemistry, 2008; 14:2956-64.

Ibrahim NK, Desai N, Legha S, Soon-Shiong P, Theriault RL, Rivera E, Esmaeli B, Ring SE, Bedikian A, Hortobagyi GN, Ellerhorst JA. Phase I and pharmacokinetic study of ABI-007, a cremophor-free, proteinstabilized, nanoparticle formulation of paclitaxel. Clin Cancer Res, 2002; 8:1038-44.

Iriti M, Faoro F. Bioactivity of grape chemicals for human health. Nat Prod Commun, 2009; 4:611-34.

Jain, S, Kumar, D, Swarnakar, NK, Thanki, K. Polyelectrolyte stabilized multilayered liposomes for oral delivery of paclitaxel. Biomaterials, 2012; 33:6758-68.

Jawahar N, Gowtham MSNR, Sumeet S. Solid lipid nanoparticles for oral delivery of poorly soluble drugs. J Pharm Sci Res, $2012 ; 4: 1848-55$

Jenning V, Schafer-Korting M, Gohla S. Vitamin A-loaded solid lipid nanoparticles for topical use: drug release properties. J Control Release, 2000; 66:115-26.

Jerome G, Patrick S, Adina L, Anthony WC. Solid Lipid Nanoparticles (SLNs): preparation and properties of Calix[4]resorcinarene derived systems. J Inclusion Phenom Macrocyclic Chem, 2004; 48:3744. 
Jin KK, Jeong SP, Chong KK. Development of a binary lipid nanoparticles formulation of itraconazole for parenteral administration and controlled release. Int J Pharm, 2010; 383:209-15.

Johanna M, Kathleen O, Ralf G, Anja SH. Fate of edible solid lipid nanoparticles (SLN) in surfactant stabilized o/w emulsions. Part 2: release and partitioning behavior of lipophilic probes from SLN into different phases of o/w emulsions. Colloids Surf A, 2018; 558:623-31.

Jores K, Mehnert W, Drechsler M, Bunjes H, Johann C, Mäder $\mathrm{K}$. Investigations on the structure of solid lipid nanoparticles (SLN) and oilloaded solid lipid nanoparticles by photon correlation spectroscopy, fieldflow fractionation and transmission electron microscopy. J Control Release, $2004 ; 2: 27-217$.

Junxian Y, Songhong Z, Shaochuan S, Zhuo C, Kejian Y, Jizhong C. Continuous production of solid lipid nanoparticles by liquid flow-focusing and gas displacing method in microchannels. Chem Eng Sci, 2009; 64:4115-22.

Kai T, Xuewei LV, Shanshan WU, Senwei X, Xiaobo H, Chenguang B. Measurement for contact angle of iron ore particles and water. ISIJ Int, 2017; 58:379-400.

Kaiser CS, Rompp H, Schmidt PC. Pharmaceutical applications of supercritical carbon dioxide. Pharmazie, 2001; 56:907-26.

Karmen TP, Stane P, Bilijana J, Slavko P, Stane S, Julijana K. A novel fluorescent probe for more effective monitoring of nanosized drug delivery systems within the cells. Int J Pharm, 2011; 1:93-384.

Shah KA, Date AA, Joshi MD, Patravale VB. Solid lipid nanoparticles of tretinoin: potential in topical delivery. Int J Pharm, 2007; $1: 163-71$.

Liu KK, Cheng CL, Chang CC, Chao JI. Biocompatible and detectable carboxylated nanodiamond on human cell. Nanotechnology, 2007; 18:325102

Liu KK, Zheng WW, Wang CC, Chiu YC, Cheng CL, Lo YS, Chen C, Chao JI. Covalent linkage of nanodiamond paclitaxel for drug delivery and cancer therapy. Nanotechnology, 2010; 21:315106.

Long C, Zhang L, Qian Y. Preparation and crystal modification of ibuprofen-loaded solid lipid microparticles. Chin J Chem Eng, 2006; $14: 518-25$.

Majid S, Farnoosh A, Ali AS, Keivan A, Nasrin H, Anwarun H, Mostafa AES Mojtaba F. Plasmonic gold nanoparticles: optical manipulation, imaging, drug delivery and therapy. J Control Release, 2019; 311-312:170-89.

Mehnert W, Mäder K. Solid lipid nanoparticles: production, characterization and applications. Adv Drug Deliv Rev, 2001; 47:165-96.

Mei L, Zhang Z, Zhao I, Huang L, Yang XL, Tang J, Feng SS Pharmaceutical nanotechnology for oral delivery of anticancer drugs. Adv Drug Deliv Rev, 2013; 65:880-90.

Minassi A, Sanchez-Duffhues G, Collado JA, Munoz E, Appendino G. Dissecting the pharmacophore of curcumin. Which structural element is critical for which action. J Nat Prod, 2013; 76:1105-12.

Mishra DK, Dhote V, Bhatnagar P, Mishra PK. Engineering solid lipid nanoparticles for improved drug delivery: promises and challenges of translational research. Drug Deliv Transl Res, 2012; 2:238-53.

Mukherjee S, Ray S, Thakur RS. Solid lipid nanoparticles: a modern formulation approach in drug delivery system. Indian J Pharm Sci, 2009; 4:349-58.

Murioz M, Garcia-Erce JA, Remacha AF. Disorders of iron metabolism: part 2. Iron deficiency and iron overloaded. J Clin Pathol, 2011; 64:287-96.

Murthy RS. Solid lipid nanoparticles as carriers for anti-cancer drugs to solid tumours. Drug Deliv, 2005; 12:385-92.

Negi JS, Chattopadhyay P, Sharma AK, Ram V. Development and evaluation of glycerate behenate based on solid lipid nanoparticles (SLNs) using hot self-nanoemulsification (SNE) technique. Arch Pharm Res, 2014; 37:70-361.

Negi JS, Chattopadhyay P, Sharma AK, Ram V. Development of solid lipid nanoparticles (SLNs) of lopinavir using hot self nanoemulsification (SEN) technique. Eur J Pharm Sci, 2013; 48:9-231.
Omwoyo WN, Ogutu B, Oloo F, Swai H, Kalombo L, Melariri P, Mahanga GM, Gathirwa JW Preparation, characterisation, and optimization of primaquine-loaded solid lipid nanoparticles. Int J Nanomed, 2014; 9:743865 .

Outuki PM, Kleinubing SA, Hoscheid J, Montanha MC, da Silva EA, DoCouto RO, Kimura E, Cardoso MLC. The incorporation of Pterodon pubescens fruit oil into optimized nanostructured lipid carriers improves its effectiveness in colorectal cancer. Ind Crops Prod, 2018; 123:719-30.

Ozaki K, Kishikawa F, Tanaka M, Sakamoto T, Tanimura S, Kohno M, Histone deacetylase inhibitors enhance the chemosensitivity of tumour cells with cross-resistance to a wide range of DNA-damaging drugs. Cancer Sci, 2008; 99:376-84.

Pandey R, Sharma S, Khuller GK. Oral SLN based antitubercular chemotherapy. Tuberculosis, 2005; 85:415-20.

Paurnima T, Saugata S, Ashok M. Physicochemical characterization of solid lipid nanoparticles comprised of glycerol monostearate and bile salts. Colloids Surf B, 2018; 172:517-25.

Peng XH, Wang Y, Huang D, Wang Y, Shin HJ, Chen Z, Spewak MB, Mao H, Wang X, Wang Y, Chen ZG, Nie S, Shin DM. Targeted delivery of cisplatin to lung cancer using ScFvEGFR-heparin-cisplatin. ACS Nano, 2011; 5:9480-9493.

Pooja D, Kulhari H, Kuncha M, Rachamalla SS, Adams DJ, Bansal V, Sistla R. Improving efficacy, oral bioavailability, and delivery of paclitaxel using protein-grafted solid lipid nanoparticles. Mol Pharm, 2016; 13:3903-12.

Poovi G, Damodharan N. Lipid nanoparticles: different preparation techniques, characterization, hurdles, and strategies for the production of solid lipid nanoparticles and nanostructured lipid carriers for oral drug delivery. Sustainable Chem Pharm, 2017; 6:37-56.

Poumellec MA, Dejode M, Figl A, Darcourt J, Haudebourg J, Sabah Y, Voury A, Martaens A, Barranger E. [Sentinel node detection using optonuclear probe (gamma and fluorescence) after green indocyanine and radio-isotope injections]. Gynecol Obstet Fertil, 2016; 4:10-207.

Preziosi P. Isoniazid: metabolic aspects and toxicological correlates. Curr Drug Metab, 2007; 8:51-839.

Wang Q, Yang Q, Cao X, Wei Q, Firempong CK, Guo M, Shi F, $\mathrm{Xu}$ X, Deng W, Yu J. Enhanced oral bioavailability and anti-gout activity of [6]-shogaol-loaded solid lipid nanoparticles. Int J Pharm, 2018; 550:24-34.

Raj K, Ashtosh S, Kajal S, Divya D, Neha G, Prem FS Preparation, characterization and in vitro cytotoxicity of Fenofibrate and Nabumetone loaded solid lipid nanoparticles. Mater Sci Eng, 2020; 106:110184.

Ramteke KH, Joshi SA, Dhole SN Solid lipid nanoparticle: a review. IOSR J Pharm, 2012; 2:34-44.

Ruckman K, Sivakumar M, Ganeshkumar PA. Methotrexate loaded solid lipid nanoparticles: for effective treatment of carcinoma. J Nanosci Nanotechnol, 2006; 6:2991-5.

Sethuraman S, Balakrishnan S, Ganesh M, Kandasamy R, Kasi PD. $\alpha$-Bisabolol loaded solid lipid nanoparticles attenuates $A \beta$ aggregation and protects Neuro-2a cells from $\mathrm{A} \beta$ induced neurotoxicity. J Mol Liq, $2018 ; 264: 431-41$

Siekmann B, Westesen K. Melt-homogenized solid lipid nanoparticles stabilized by the nonionic surfactant tyloxapol. I. Preparation and particle size determination. Pharm Pharmacol Lett, 1994; 3:194-7.

Sjostrom B, Bergenstahl B. Preparation of submicron drug particles in lecithin-stabilized $\mathrm{o} / \mathrm{w}$ emulsions: model studies of the precipitation of cholesteryl acetate. Int J Pharm, 1992; 88:53-62.

Soliman M-S, Shirin Z, Elaheh E-A. Piroxicam loaded solid lipid nanoparticles for topical delivery: preparation, characterization and in vitro permeation assessment. J Drug Delivery Sci Technol, 2018; 47:427-33.

Sonia T, Rossella R, Silvia M, Giuseppe PV, Annarita SL, Fabio M, Roberta C. Solid lipid nanoparticles made of trehalose monooleate for cyclosporin-A topic release. J Drug Delivery Sci Technol, 2019; 49:563-9.

Souto EB, Wising SA, Barbosa CM, Millar RH. Development of a controlled release formulation based on SLN and NLC for topical clotrimazole delivery. Int J Pharm, 2004; 1:71-7. 
Stoehr LC, Gonzalez E, Stampfl A, Casals E, Duschl A, Puntes V, Oostingh GJ, Shape matters: effects of silver nanospheres and wires on human alveolar epithelial cells. Part Fibre Toxicol, 2011; 8:1-15.

Subramony JA. Apomorphine in dopaminergic therapy. Mol pharm, 2006; 3:380-5.

Rizvi SZH, Shah FA, Khan N, Muhammad I, Ali KH, Ansari MM, Din FU, Qureshi OS, Kim KW, Choe YH, Kim JK, Zeb A. Simvastatinloaded solid lipid nanoparticles for enhanced anti-hyperlipidemic activity in hyperlipidemia animal model. Int J Pharm, 2019; 560:136-43.

Thakur R, Gupta RB. Rapid Expansion of Supercritical Solution with Solid Cosolvent (RESS-SC) process: formation of griseofulvin nanoparticles. Ind Eng Chem Res, 2005; 44:7380-7.

Vajpayee V, Yang YJ, Kang SC, Kim H, Kim IS, Wang M, Stang PJ, Chi K-W. Hexanuclear self-assembled arene-ruthenium nano-prismatic cages: potential anticancer agents. Chem Commun, 2011; 47:5184-6.

Valodkar, M, Jadeja, RN, Thounaojam, MC, Ranjitsinh VD, Sonal $\mathrm{T}$. In vitro toxicity study of plant latex capped silver nanoparticles in human lung carcinoma cells. Mater Sci Eng C, 2011; 31:1723-8.

Van de Ven H, Vermeersch M, Shunmugaperumal T, Vandervoort J, Maes L, Ludwig A. Solid lipid nanoparticle (SLN) formulations as a potential tool for the reduction of cytotoxicity of saponins. Pharmazie, $2009 ; 3: 6-172$

Vandana BP, Amit GM. Preparation and characterization of solid lipid nanoparticles-based gel for topical delivery. Pharm Nanotechnol, 2019; 2000:293-302.

Venishetty VK, Chede R, Komuravelli R, Adepu L, Sistla R, Diwan PV. Design and evaluation of polymer coated carvedilol loaded solid liquid nanoparticles to improve the oral bioavailability: a novel strategy to avoid intraduodenal administration. Colloids Surf B, 2012; 95:1-9.

Weber S, Zimmer A, Pardeike J. Solid lipid nanoparticles (SLN) and nanostructured lipid carriers (NLC) for pulmonary application: a review of the state of the art. Eur J Pharm Biopharm, 2014; 86:7-22.

WIPO - Search International and National Patent Collections. Available via https://patentscope.wipo.int/search/en/search.jsf (Accessed 12 April 2020).
Wolfgang M, Karsten M. Solid lipid nanoparticles production, characterization and applications. Adv Drug Deliv Rev, 2001; 47:165-96.

Kang X, Chen H, Li S, Jie L, Hu J, Wang X, Qi J, Ying X, Du Y. Magnesium lithospermate B loaded PEGylated solid lipid nanoparticles for improved oral bioavailability. Colloids Surf B Biointerfaces, 2018; 161:597-605.

Yadav P, Soni G, Mahor A, Alok S, Singh PP, Verma A. Solid lipid nanoparticles; an effective and promising drug delivery system a review. Int J Pharm Sci Res, 2014; 5:1152-62.

Yap SP, Yuen KH, Lim AB. Influence of route of administration on the absorption and disposition of alpha- gamma- and delta-tocotrienols in rats. J Pharm Pharmacol, 2003; 55:53-8.

Zhang Y, Li Z, Zhang K, Yang G, Wang Z, Zhao J, Hu R, Feng $\mathrm{N}$. Ethyl oleate-containing nanostructured lipid carriers improve oral bioavailability of trans-ferulic acid as compared with conventional solid lipid nanoparticles. Int J Pharm, 2016; 1:57-64.

Zafar N, Fessi H, Elaissari A. Cyclodextrin containing biodegradable particles: from preparation to drug delivery applications. Int J Pharm, 2014; 461:351-66.

Zhang ZH, Zhang YL, Zhou JP, Lv HX. Solid lipid nanoparticles modified with stearic acid-octaarginine for oral administration of insulin Int J Nanomed, 2012; 7:9-3333.

Zubris, KAV, Colson, YL, Grinstaff, MW. Hydrogels as intracellular depots for drug delivery. Mol Pharmaceul, 2012; 9:196-200.

\section{How to cite this article:}

Sastri KT, Radha GV, Pidikiti S, Vajjhala P. Solid lipid nanoparticles: Preparation techniques, their characterization, and an update on recent studies. J Appl Pharm Sci, 2020; 10(06):126-141. 